Revista lus et Praxis, Año 19, No 1, 2013, pp. 35 - 76

ISSN 0717 - 2877

Universidad de Talca - Facultad de Ciencias Jurídicas y Sociales

"Problemas teóricos en torno a las potestades normativas y la necesaria redefinición de la reserva legal en el Estado constitucional chileno"

Kamel Cazor

\title{
PROBLEMAS TEÓRICOS EN TORNO A LAS POTESTADES NORMATIVAS Y LA NECESARIA REDEFINICIÓN DE LA RESERVA LEGAL EN EL ESTADO CONSTITUCIONAL CHILENO*
}

\author{
THEORETICAL PROBLEMS AROUND THE REGULATORY POWERS AND \\ THE NECESSARY REDEFINITION OF THE LEGAL RESERVE OF THE CHILEAN \\ CONSTITUTIONAL STATE
}

Kamel CAZOR**

\begin{abstract}
RESUMEN
En el presente trabajo se abordan los principales problemas teóricos que existen en torno a las potestades normativas, particularmente, en lo referente al sistema de reserva legal en vigor. Se estudia, por una parte, el problema orgánico-representativo del Parlamento y la paradoja de la primacía regulativa de la ley, todo ello a propósito de la concepción constitucional que sustenta nuestro sistema fundamental y, por otra parte, se examina el problema teórico-conceptual de la ley que está presente en nuestra Constitución. Todo esto a fin de plantear la necesaria redefinición de la reserva legal en Chile.
\end{abstract}

\section{ABSTRACT}

This paper examines the main theoretical problems that exist around the regulatory powers, particularly in relation to the legal reserve system in force. On the one hand, it is studied the organic-representative problem of Parliament and the paradox of the regulatory primacy of law, all of which concerning the constitutional conception underlying our fundamental system and on the other hand, it is examined the theoretical conceptual problem of law, that is present in our Constitution. Altogether in order to set out the necessary redefinition of the legal reserve in Chile.

PalabRas Clave

Potestades Normativas, Reserva Legal, Estado Constitucional y Democrático

KEYWORDS

Regulatory powers, Legal Reserve, Constitutional State, Democratic State

* Trabajo recibido el 7 de marzo de 2013 y aprobado el 8 de abril de 2013.

** Doctor en Derecho; Profesor Asociado de Derecho Constitucional en la Universidad Católica del Norte. Correo electrónico: cazor@ucn.cl. Este trabajo forma parte del Proyecto Fondecyt Regular № 1110376 (2011-2012) titulado "La reserva de ley como límite del legislador democrático y la necesidad de redefinir su función en el Estado Constitucional chileno", del que su autor es investigador principal. 
I. El problema orgánico-representativo del Parlamento y la paradoja

DE LA PRIMACÍA REGULATIVA DE LA LEY: A PROPÓSITO DE LA CONCEPCIÓN CONSTITUCIONAL QUE SUSTENTA NUESTRO SISTEMA FUNDAMENTAL

El presente estudio debe, necesariamente, partir del supuesto de que, por una parte, existe una clara debilidad teórico-regulativa en la ordenación de las potestades normativas en Chile, y que, por otra parte, su configuración se caracteriza por una heterogeneidad de reservas legales y múltiples combinaciones que pueden plasmarse entre ellas ${ }^{1}$. La principal causa de esta conclusión, tiene su origen en la existencia de una falta de sistematicidad, que se pretendió adoptar en definitiva, al querer configurarse un criterio en torno al concepto de ley, quedando de manifiesto, en este punto, claras deficiencias en el proceso constituyente, que es necesario reconducir teóricamente. En este sentido, es historia conocida la disparidad de criterios que tuvo la Junta de Gobierno (titular del poder constituyente de la época) con la propuesta de la Comisión de Estudios de la Nueva Constitución (comisión asesora técnica), sobre la temática de la relación ley-reglamento, prevaleciendo, en último término, el criterio de la Junta militar.

Este contexto analítico habría que situarlo, además, dentro de la concepción de democracia fundamentalista o fundamentalismo constitucional, que sustenta el sistema de la Carta de 1980, caracterizada, siguiendo a Ackerman, porque "el pueblo no tiene la autoridad necesaria para cambiar la Constitución (...) esto no significa que para el fundamentalismo no haya lugar para un gobierno democrático y popular, pero sí, que un gobierno democrático y popular debe estar restringido por el respeto a ciertos principios y a ciertos derechos. En otras palabras - prosigue este autor-, el fundamentalismo tiene un compromiso con la democracia aunque tiene un compromiso más profundo con el respeto a los derechos fundamentales". Miembros de esta escuela difieren en "cuáles son los derechos fundamentales que encorsetan la decisión popular", de ahí que conservadores (Epstein), liberales (Dworkin o Nino) y colectivistas (Fiss), "sean partidarios de una misma teoría constitucional: para los fundamentalistas cualquiera sea el contenido de los derechos, la Constitución está, primero y principal, comprometida con su protección. De hecho, de acuerdo a esta teoría, la razón de ser de los derechos es que ellos sirven como vallas a la prosecución de objetivos colectivos por parte de instituciones democráticas (...) En la visión fundamentalista si los derechos fuesen a ceder frente a decisiones colectivas ellos no satisfarían el rol que están llamados a desempeñar"2.

1 Cazor Aliste, Kamel y Pfeffer Urquiaga, Emilio, "La búsqueda de criterios orientadores en la configuración de las potestades normativas en Chile", lus et Praxis, vol.15, n.1, 2009, pp. 191-227.

2 Ackerman, Bruce y Rosenkrantz, Carlos, "Tres concepciones de la democracia constitucional", Cuaderno y debates, $N^{\circ} 29$, Fundamentos y alcances del control judicial de constitucionalidad, Centro de Estudios Constitucionales, Madrid, 1991, pp. 15, 22 y 23. 
En este mismo sentido, se concluye, como "para los fundamentalistas los derechos ['Derechos'] son definidos con independencia del proceso democrático (...) la Constitución es, primero y principal, un instrumento de protección de 'Derechos' de tal modo que sólo después que estos 'Derechos' son garantizados el proceso democrático puede abrirse su propio camino" ${ }^{3}$. Expresado de otro modo, existe un "núcleo de lo no decidible por la democracia política", ${ }^{4}$ y situados en el plano constitucional chileno, dicho "coto vedado" lo podríamos encontrar en un verdadero "mínimo liberal constitucionalmente garantizado".

De ahí que, en esta perspectiva doctrinal, se parte del Derecho para incidir en la realidad (como una especie de Constitución racional-normativa ${ }^{5}$ ), practicando no un constitucionalismo funcional sino, más bien, beligerante, resolviendo el conflicto en favor de la Constitución. Sin embargo, esta perspectiva posee evidentes riesgos: por un lado, "confiar en el Derecho por sí mismo, por sus características técnicas, resolviéndose el uso del Derecho en la búsqueda prevalente o exclusiva de su funcionalidad racionalizadora, deslizándose al fin hacia una coincidencia con posturas puramente formalistas"; por otro lado, se pone toda la esperanza "en el despliegue de las potencialidades que alberga la normatividad constitucional", generando una hiperconstitucionalización, es decir, "en la Constitución debe buscarse la solución de todos los problemas (...) lo que conduce a estimar que todo está ya decidido, que hubo un momento en el que se decidió definitivamente el futuro, que, en consecuencia, la capacidad de decisión está 'congelada' y, por tanto, se excluyen o reducen considerablemente las posibilidades del principio democrático y de una ciudadanía activa, con lo que termina coincidiendo con posiciones antidemocráticas, aunque formalmente constitucionales, que completan la contraposición entre Estado de Derecho y Estado democrático con clara opción por el primero ante su perfección técnica frente al segundo, dada su imperfección política" ${ }^{\prime 6}$.

El contexto de la temática abordada en este estudio, impide entrar en la trascendental controversia de la relación entre democracia (ley) y constitucionalismo (derechos fundamentales) ${ }^{7}$, motivada a raíz de "la dificultad para admitir desde los parámetros de una teoría política democrática que se impongan

3 ACKERMAN, "Tres concepciones", cit. nota n. 2, p. 25.

${ }^{4}$ De Cabo Martín, Carlos, Sobre el concepto de ley, Editorial Trotta, Madrid, 2000, p. 12.

${ }^{5}$ Verdugo MarinKovic, Mario, "Asamblea constituyente: ¿Invitación a un quiebre institucional?", Diario Constitucional, 2012. En: http://diarioconstitucional.cl/mostrararticulo.php?id=192 [visitado el 03/09/2012].

${ }^{6}$ De Cabo, Sobre el, cit. nota n. 4, pp. 12-13.

7 ELSTER, Jon y SLAGSTAD, Rune, Constitucionalismo y democracia, Fondo de Cultura Económica, MéxiCo, 1999; y SChNeider, Hans Peter, Democracia y Constitución, Centro de Estudios Constitucionales, Madrid, 1991. 
límites constitucionales a la capacidad de deliberación de los ciudadanos y al poder de decisión de las mayorías" ${ }^{\prime \prime}$. Conviene, no obstante, citar brevemente las perspectivas de algunos autores, que ponen en evidencia la dicotomía entre constitucionalismo y democracia.

Sobre el particular, Neil MacCormick expresa que "la democracia funciona sólo donde hay alguna forma de orden constitucional bien establecido", desde esta perspectiva -continúa- "el constitucionalismo es un requisito previo a la democracia", que hace posible y viable esta última; por ello no se trata de una democracia pura y simple, sino de una democracia cualificada por el constitucionalismo ${ }^{9}$. Sin embargo, a la luz de nuestra peculiar experiencia de constitucionalismo fundamentalista (basada, además, en una noción de constitucionalismo restringido y fuerte, utilizando la terminología de Paolo Comanducci $\left.{ }^{10}\right)$, resulta poco sustentable $-y$ hasta riesgosa- la idea de que el constitucionalismo sea un prerrequisito de la democracia y de que ésta no representa un ideal autosuficiente. Motivo por el cual, nuestro razonamiento debe ir mucho más allá, ya que es un hecho ineludible que la democracia, sustentada en la regla de la mayoría, se trata de un principio configurador de naturaleza material, cuyo procedimiento esencialmente busca el desarrollo y garantía de los derechos y libertades fundamentales, entendiendo por tales a aquellos asociados al propio principio democrático, en particular, como al resto de los derechos fundamentales, en general. Sería insostenible y poco realista, por lo tanto, cualquier teoría de la Constitución, cuyo ideal constitucional se convierta en un freno para el proceso democrático, ya que, a largo plazo, afectaría la propia sustancialidad de la Carta Fundamental ${ }^{11}$.

Cuestión que, además, citando a Víctor Ferreres, debemos conciliar con la tensión existente entre justicia constitucional y democracia, dentro de lo que

${ }^{8}$ Peña Freire, Antonio, "Constitucionalismo Garantista y Democracia", Revista Crítica Jurídica, 2003, $N^{\circ} 22$, p. 32.

9 MacCormick, Neil, "Constitucionalismo y democracia", Anuario de Derechos Humanos, Universidad Complutense de Madrid, 1988-89, № 5, p. 380.

${ }^{10}$ Según Paolo Comanducci, "el constitucionalismo en sentido amplio es la ideología que requiere la creación de una -cualquiera-Constitución, a fin de limitar el poder y prevenir el despotismo. El constitucionalismo en sentido restringido -prosigue- es la ideología que requiere la creación de un específico tipo de Constitución a fin de limitar el poder y de prevenir el despotismo (...) El constitucionalismo débil -continúa- es la ideología que requiere una Constitución solamente para limitar el poder existente, sin prever una específica defensa de los derechos fundamentales. El constitucionalismo fuerte (o liberal) es la ideología que requiere una Constitución para garantizar los derechos y las libertades fundamentales frente al poder estatal" ("Formas de (Neo) constitucionalismo: un análisis metateórico", Coordinador Miguel Carbonell, Neoconstitucionalismos, Trotta, Madrid, 2005, pp. 76-77). A la luz de lo expuesto, resulta claro que la actual Carta chilena, estaría más cercana a las concepciones del constitucionalismo en sentido restringido y fuerte.

11 Cazor y Pfeffer, "La búsqueda", cit. nota n. 1, pp. 191-227. 
se denomina "objeción democrática", ya que "aunque, en última instancia, nos parezca legítimo el control judicial de la constitucionalidad de las leyes, debemos reconocer que esta institución entraña un coste democrático, pues existe una importante conexión entre el principio democrático, por un lado, y la aprobación de una ley por la mayoría de un parlamento elegido por los ciudadanos, por el otro (...) La democracia, en efecto, está conceptualmente ligada a la existencia de un procedimiento que otorga a los ciudadanos unas mismas oportunidades para participar con su voz y con su voto en las discusiones y aprobación de las decisiones colectivas (...) Como Jeremy Waldrom ha destacado, la regla de la mayoría tiene un valor intrínseco, en la medida en que cuenta con todos los votos por igual, no prefiere un resultado frente a otro (...) Es decir, la regla de la mayoría trata a los ciudadanos como iguales, y es neutral en cuanto a las distintas posiciones que son objeto de discusión"112.

Como es fácil apreciar, no se trata para nada de un tema pacífico, muy bien sintetizado en las ideas de José Joaquín Gomes Canotilho. Señala este autor: La dicotomía 'demócratas puros'/'constitucionalistas puros' no significa en modo alguno que los 'constitucionalistas' no sean 'demócratas' y los 'demócratas' no sean 'constitucionalistas'. El constitucionalismo considera fundamental el proceso democrático y la teoría democrática reconoce la importancia de los derechos fundamentales garantizados en la Constitución. La divergencia básica radica en la forma de proteger estos derechos y los bienes constitucionales a ellos inherentes. Los 'demócratas puros' creen en la primacía del autogobierno democrático y en el proceso democrático como la forma de asegurar la protección de las libertades y derechos de las personas. Los 'constitucionalistas' toman el proceso político como base de las políticas públicas en relación a los derechos, pero el proceso político no es suficiente para avalar la justeza de esas políticas"13.

Es aquí en donde reside, esencialmente, la gran paradoja en el sistema constitucional chileno.

Ya que, por una parte, se circunscribe a la noción constitucional de la democracia fundamentalista, dándole una clara preeminencia al Estado de Derecho sobre el Estado democrático, en donde la capacidad de decisión está prácticamente "congelada" por el acuerdo constituyente y, por tanto, se excluyen o reducen considerablemente las posibilidades a la democracia, especialmente aquella que se manifiesta a través de las decisiones legislativas. Y, por la otra, se

12 Ferreres Comella, Víctor, Una defensa del modelo europeo de control de constitucionalidad, Marcial Pons, Madrid-Barcelona, 2011, pp. 139-140.

13 Gomes Canotilho, José Joaquín, Teoría de la Constitución, Dykinson, Madrid, 2004, pp. 112 y 113. 
le da una amplia esfera material de regulación a la ley, que, a lo menos teóricamente, sería la más genuina portadora del principio democrático. Sin embargo, mientras más capacidad regulativa se le entrega a la ley, existe menos democracia en la decisión (particularmente si nos centramos en el principio mayoritariorepresentativo, que se manifiesta en el sistema electoral en vigor $\left.{ }^{14}\right)$, lo que es absolutamente contradictorio y paradójico, pero absolutamente explicable a la luz de nuestro sistema constitucional fundamentalista, el que además, como ya lo hemos mencionado, se sustenta en una noción de hiperconstitucionalización, congelando la capacidad de decisión "democrática".

Expresado de otro modo, la primacía regulativa de la ley en nuestro país, convive con un marcado carácter no mayoritario en la decisión legislativa, lo que es claramente disfuncional, toda vez que la regla de la mayoría es consustancial y revaloriza la ley, ya que ella es la que mejor traduce el principio de igualdad y la representatividad de los ciudadanos, produciendo en última instancia la articulación entre el Estado y sociedad. Y afianza este "círculo virtuoso", la noción fundamentalista constitucional que sustenta nuestra actual Carta, alejando cualquier posibilidad de decisión democrático-mayoritaria. Un cerrojo perfecto, que, sin lugar a dudas, ha generado un efecto estabilizador a nivel institucional, pero que a la larga está produciendo una peligrosa desvinculación entre las decisiones estatales y los ciudadanos.

El panorama anterior, entre otros asuntos y citando a López Guerra, produce como resultado "problemas como la esclerotización de los mecanismos de representación, que conducen a una desconfianza en la clase política y a un creciente abstencionismo ciudadano, la dificultad para la expresión de alternativas políticas a las ofrecidas por las fuerzas ya instaladas en el sistema, y como consecuencia, la falta de opciones renovadoras, frente a situaciones de crisis, [que además] se encuentran íntimamente relacionados con las deficiencias en las vías de traslación de la opinión y voluntad ciudadana a las instituciones

\footnotetext{
14 Para explicar esta aseveración, debemos necesariamente situarnos en el contexto de que existe en Chile un problema democrático (crisis de participación y agotamiento del sistema político representativo de los parlamentarios), el cual se manifiesta, dentro de la primacía regulativa de la ley ya mencionada, en la traslación de la voluntad popular a la vida estatal, particularmente en un Parlamento generado por el sistema electoral binominal-mayoritario y las consecuencias en su conformación que ello acarrea. En efecto, se produce el inquietante fenómeno de que, en la práctica, la soberanía nacional se ve sustituida por la soberanía parlamentaria, es decir, en última instancia, solamente la representación parlamentaria se convierte en soberana. Que, según las últimas encuestas autorizadas, no representan más del 40\% del electorado nacional. En efecto, según encuesta Adimark (marzo de 2012), el 67\% de los encuestados desaprueba la gestión de la Cámara de Diputados (23\% de aprobación); el 63\% de los encuestados desaprueba la gestión del Senado (26\% de aprobación); 63\% de los encuestados desaprueba la gestión de la oficialista Coalición por el Cambio (24\% de aprobación); y, finalmente, $67 \%$ de los encuestados desaprueba la gestión de la opositora Concertación (21\% de aprobación). Cifras que, en mayor o menor medida, han sido constantes en el último tiempo.
} 
estatales denunciadas [ya en esa época] por Carré respecto de la Constitución de la Tercera República"15.

Ahora bien, la pregunta que surge por sí sola es: ¿cómo vinculamos esta concepción constitucional fundamentalista y racional-normativa, con el concepto y funcionalidad de la ley dentro de nuestro ordenamiento jurídico? En el desarrollo posterior del trabajo trataremos de responder a esta interrogante, el cual comenzaremos a dilucidar poniendo en evidencia algunas consideraciones en torno a la ley.

Por un lado, se debe indicar que en la ley se mezclan, necesariamente, dos planos, el jurídico y el político (ya que, por ejemplo, las discrepancias entre las diferentes interpretaciones de la reserva legal son, sobre todo, desacuerdos de carácter político, y que "responden a diferentes concepciones sobre la sociedad, las relaciones entre sociedad y Estado, y las funciones que le corresponden al Estado"16), es decir, "se configura así como categoría central del Estado constitucional al vincular en forma unitaria el principio (del Estado) democrático y el postulado del Estado de Derecho de manera que mediante la ley se realiza la propuesta básica de la Constitución de producir la articulación Estado-sociedad"17. Por otro lado, hay que señalar que en esta intersección de lo jurídico y lo político es donde resulta la coexistencia en el concepto de ley de elementos formales y materiales: "así, en lo que puede considerarse el elemento material, que hace referencia al contenido y por tanto a la antes referida articulación Estado-sociedad, está presente un cierto ingrediente formal como es el de aquel tipo de eficacia que afecta a ambos (su común sometimiento a la ley), y en el formal, que hace referencia al tipo de norma definida por su procedencia y formación, está también presente un aspecto material (político) como es el que resulta de incorporar el principio democrático". De ahí que la ley cumpla una función jurídico formal (conversión en reglas de los principios constitucionales) y una función jurídico material (ejercicio de competencias normativas específicas) ${ }^{18}$.

Dentro del contexto de problematización expuesto en este acápite, queda clara la no fácil tarea que debe enfrentarse en el sistema constitucional chileno, sobre todo si estamos en presencia de una temática que no sólo debe

\footnotetext{
15 López Guerra, Luis, "Carré de Malberg: de la soberanía nacional a la soberanía popular", Introducción al libro La ley, expresión de la voluntad general (Estudio sobre el concepto de la ley en la Constitución de 1875), Marcial Pons, Madrid-Barcelona, 2011, p. 18.

16 Melero Alonso, Eduardo, "La flexibilización de la reserva de ley", Revista Jurídica Universidad Autónoma de Madrid, n. 10, 2004, p. 110.

17 De Caвo, Sobre el, cit. nota n. 4, p. 22.

18 De Cabo, Sobre el, cit. nota n. 4, p. 23.
} 
circunscribirse a la mera discusión teórica ("en la que sólo la 'interpretación' de la Constitución tiene algo que decir"), sino también considerar la práctica legislativa y jurisprudencial; de ahí que se debe acercar la distancia existente en este tema entre teoría y práctica ${ }^{19}$. Sin embargo, por la perspectiva del estudio que nos convoca, solamente nos adentraremos en la configuración teórica de esta trascendental materia de la reserva legal y del concepto de ley que la sustenta.

Finalmente, no hay que olvidar que, en general, "los sistemas constitucionales han modificado profundamente el entendimiento sobre la función del legislador y, por ello mismo, sobre la reserva de ley"20; de ahí que en el sistema constitucional chileno se justifique volver sobre este clásico tema y, en la medida de lo posible, plantear una necesaria redefinición de nuestra garantía de reserva legal, a fin de lograr su reconciliación con el principio democrático y el Estado de Derecho.

\section{El PROBLEMA TEÓRICO-CONCEPTUAL DE LA LEY EN NUESTRO ORDENAMIENTO CONSTITUCIONAL \\ II.1. La particular configuración del sistema de reserva legal en nuestra Constitución}

Como punto de partida, cabe recordar que era un lugar común en la doctrina nacional la constante alusión que se hacía sobre la inspiración francesa que tenía nuestra actual estructura constitucional en torno a la reserva legal (a partir de lo cual, derivaban el denominado "dominio legal máximo"). Sin embargo y ahí viene la confusión en esta materia, en definitiva, el objetivo del constituyente (Junta de Gobierno) no fue incorporar en estricto sentido el sistema francés en la ordenación de la relación ley-reglamento, sino que, en la práctica, habría conservado el diseño de la anterior Constitución, en el contexto de mantener como principio la primacía de la ley como norma de clausura del sistema normativo; pero claramente le agregó nuevos elementos, que no estaban considerados en la Carta de 1925, como, por ejemplo, la reserva material de ley o la potestad reglamentaria independiente ${ }^{21}$. De ahí que Ribera, acertadamente, sobre el particular, haya concluido lo siguiente: "A la luz de las propias disposiciones constitucionales y de los antecedentes internos de la Junta de Gobierno es po-

19 Baño León, José María, Los límites constitucionales de la potestad reglamentaria, Civitas, Madrid, 1991, pp. 19 y 21.

20 Baño León, Los límites, cit. nota n. 19, p. 24.

21 Cazor Aliste, Kamel y Guiloff Titiun, Matías, "Problemas conceptuales y de funcionalidad de la reserva legal en Chile", Las Fuentes Formales del Derecho Público (Coordinador Hugo Tórtora), Editorial Metropolitana, Santiago, 2012, p. 325. 
"Problemas teóricos en torno a las potestades normativas y la necesaria redefinición de la reserva legal en el Estado constitucional chileno"

sible establecer que el objetivo final del Poder Constituyente no fue incorporar en el nuestro el sistema francés, pero tampoco mantener aquél vigente durante la Constitución de 1925, sino que superar la situación existente a la fecha, cuidando de evitar un eventual desequilibrio entre ambos poderes" ${ }^{\prime 22}$.

Este pretendido objetivo del constituyente, tiene su reflejo en el hecho de que en nuestro ordenamiento constitucional se reconocen diversas clases de reserva de ley, las que pueden clasificarse de conformidad a variados criterios.

En la doctrina nacional, por ejemplo, Gonzalo García plantea la clasificación entre reservas legales complementarias, limitativas, regulatorias y negativas ${ }^{23}$. Para Teodoro Ribera, en cambio, "el ámbito a regular [de la reserva legal] está determinado en cada caso por el constituyente, al utilizar expresiones diversas para encomendar al legislador dicha tarea"; así, en lo referente a la extensión de las materias posibles de normar, indica Ribera: "La extensión o ámbitos de las materias posibles a regular es en el artículo 60 [63] meramente enumerativa, constituyendo en sí un campo legal mínimo y no máximo, dada la vigencia del mencionado numeral 20 (...) Sin embargo -prosigue-, en lo que respecta a la intensidad de la regulación, cabe distinguir entre los mandatos precisos que la Constitución contempla a favor del legislador mediante disposiciones expresas en cada caso, con la atribución genérica que lo autoriza a normar nuevas materias no consignadas en los numerales 1 a 19 del artículo 60 [63], en los términos exigidos en el numeral 20 ya citado"24. En esta última situación, para este autor, "en los casos no previstos expresamente en la Constitución, cabe aplicar el numeral 20 del artículo 60 [63], esto es, una limitación en lo relativo a la intensidad o profundidad de la regulación, mas no en cuanto al contenido que puede alcanzar" 25 .

Para nosotros, por una parte, de acuerdo al grado de especificidad con que la Constitución recoge la reserva, ésta puede ser especial o general (por ejemplo, en materia de derechos fundamentales es posible constatar una reserva general derivada del art. $63, \mathrm{~N}^{\circ} 2$ y 20 , art. 19, $\mathrm{N}^{\circ} 26$, y art. 64 que plantea la prohibición de la delegación legislativa, cuando ésta incida sobre las garantías constitucionales). Por otra parte, de conformidad al nivel de especificidad material con que la Carta la recepta, puede vislumbrarse una reserva material y otra

22 Ribera Neumann, Teodoro, "Reserva legal, potestad reglamentaria y Constitución de 1980", Revista de Derecho Público, vol. 63, 2001, pp. 471-489. Ver también: Ribera Neumann, Teodoro, "Reserva legal y potestad reglamentaria en la Constitución de 1980. Antecedentes inéditos de la Junta de Gobierno", Documento inédito, 2000, p. 6.

${ }^{23}$ García Pino, Gonzalo, La reserva legal de derechos constitucionales: ipoder legislativo contra la administración? Ediciones Universidad Alberto Hurtado, Santiago, 2004, p.172.

${ }^{24}$ Ribera, "Reserva", cit. nota n. 22, p. 481.

25 Ribera, "Reserva", cit. nota n. 22, p. 482. 
formal (esta última, por vía del art. 63, № 20, que establece las denominadas leyes de bases generales; sin olvidar tampoco la especificidad material de las leyes orgánicas y de quórum calificado).

Cabe destacar que en virtud del numeral 20 del artículo 63 (que consigna como materia de ley: "Toda otra norma de carácter general y obligatoria que estatuya las bases esenciales de un ordenamiento jurídico") se han suscitado los mayores problemas interpretativos en torno a esta temática de las potestades normativas, especialmente debido a la amplitud de su formulación, lo que ha generado un problema teórico-conceptual de la ley en nuestro ordenamiento, e igualmente ha dificultado la instrumentalización de la potestad reglamentaria independiente.

Dentro de esta problemática, sostuvo en su oportunidad Luz Bulnes que el numeral vigésimo introducido por la Junta Militar, estableció las denominadas "leyes de bases esenciales", entendiendo que éstas habilitan al legislador para que regule, respecto de los ordenamientos jurídicos, sólo las bases o contenidos fundamentales, manteniendo las características de generalidad que debe tener la ley y de impedir la regulación de materias que podrían abordarse vía reglamentaria, es decir, esta forma de ley involucra restaurar "su carácter permanente, general y abstracto que tiene por objeto establecer las bases y principios directrices sobre una materia, a las cuales debe sujetarse el Poder Ejecutivo para poner en ejecución una determinada materia, mediante el ejercicio de su potestad reglamentaria normal"26. Con ello se pretendió resaltar que a la ley le correspondía sólo abordar el núcleo esencial de la materia que se propone regular, dejando entregado al reglamento de ejecución su desarrollo e implementación, marcando una colaboración entre la ley y el reglamento ejecutivo que es indisoluble ${ }^{27}$. Sin perjuicio, habría que agregar, de la necesaria interacción que debe realizarse con el reglamento autónomo o independiente, cuando las posibilidades regulatorias de la Carta lo hagan viable.

En consecuencia, en torno al ámbito de la ley, a partir de lo preceptuado en el $N^{\circ} 20$ del artículo 63, se han sostenido las siguientes tesis en la doctrina nacional ${ }^{28}$ :

26 Bulnes Aldunate, Luz, "Leyes de Base y Potestad Reglamentaria en la Constitución de 1980", Revista de Derecho de la Universidad Católica de Valparaíso, № 6, 1982, p. 141.

27 Carmona Santander, Carlos, "Tres problemas de la potestad reglamentaria: Estado de la cuestión y proyecciones", Revista de Derecho del Consejo de Defensa del Estado, Año 1, N 3, 2001, p. 32.

${ }^{28}$ Sobre esta sistematización de las diversas tesis de la doctrina nacional, ver también: BuGueÑo ConTRERAS, José, "La potestad reglamentaria autónoma en la Constitución chilena: La norma de clausura del ordenamiento jurídico", Tesis de Licenciatura, Escuela de Derecho, Universidad Católica del Norte, Coquimbo, 2012, pp. 54-78. 
a) Esta norma establecería, según Hernán Molina, una reserva legal que no describe contenidos, objetos o materias, ya que se está refiriendo a una nueva categoría de ley ("ley de bases") y, por consiguiente, se habría inspirado en el constitucionalismo clásico ${ }^{29}$, pero con una salvedad, la ley debe ser en su sentido material y de bases esenciales ${ }^{30}$, es decir, identifica las características propias de este tipo de normas (la generalidad, obligatoriedad y las bases esenciales) con el concepto material de ley.

b) El sistema de distribución de competencias, agrega José Luis Cea, "no difiere esencialmente, del estatuido en la Constitución de 1925, porque el cambio de redacción y las proclamaciones son insuficientes, para convertir las apariencias en una innovación fundamental y práctica"31.

c) La pretendida reserva máxima legal, por ende, se ha convertido nuevamente en un dominio mínimo lega ${ }^{32}$, toda vez que el legislador puede extenderse a cualquier materia aunque sea sólo en sus bases esenciales.

d) El artículo 63 se trataría de una norma de competencia atributiva no constitucionalmente clausurada ${ }^{33}$. En el sentido de que, en principio, la competencia del legislador sería excepcional y de atribución, luego también, en principio, el reglamento sería la norma de clausura del ordenamiento jurídico ${ }^{34}$. Sin embargo, a raíz de que el dominio legal máximo no se encuentra en un estricto marco de excepcionalidad, sino en un ámbito de competencia no constitucionalmente clausurado, ello, sin duda, reduce la operatividad de la potestad reglamentaria y relativiza su carácter de norma de clausura ${ }^{35}$.

e) El artículo 63 no consagra un catálogo taxativo de materias, toda vez que el numeral 20 entregó al legislador la facultad para extenderse a cualquier materia, pero estableciendo, en cuanto a su extensión, que dicha normativa deba ser general, obligatoria y estatuir las bases esenciales de un ordenamiento jurídico. En consecuencia, el encabezado "sólo son materias de ley" establece un campo mínimo reservado al legislador ${ }^{36}$.

\footnotetext{
${ }^{29}$ Molina Gualta, Hernán, Derecho Constitucional, Editorial Andalién, Concepción, 1998, p. 293.

${ }^{30}$ Molina, Derecho, p. 292.

31 Cea Egaña, José Luis, "Dominio legal y reglamentario en la Constitución de 1980", Revista Chilena de Derecho, vol. 11, 1984, p. 431.

32 Caldera Delgado, Hugo, Tratado de Derecho Administrativo, Tomo II, Ediciones Parlamento, Santiago, 2001, p. 232.

${ }^{33}$ Cazor Aliste, Kamel, La sumisión a Derecho de los actos y disposiciones del Presidente de la República, Tomo I, Ediciones Universidad Central de Chile, Santiago, 2002, p. 171.

${ }^{34}$ Cazor, La sumisión, cit. nota n. 33, p. 98.

35 Cazor, La sumisión, cit. nota n. 33, p. 98.

36 Ribera, "Reserva legal", cit. nota n. 22, p. 480.
} 
f) El Tribunal Constitucional ha expresado que el referido $N^{\circ} 20$, del artículo 63, "....) está redactado en términos excesivamente amplios e indeterminados sin señalar directamente el contenido de aquello que debe ser materia de ley. La disposición más bien precisa tres caracteres formales, a saber: a) que sea "general", b) que sea "obligatoria" y c) que "estatuya las bases esenciales de un ordenamiento jurídico", sin establecer cuáles son las materias de ese ordenamiento jurídico que comprende o a las cuales se extiende (...)" (considerando № 24, sentencia Rol №325-2001). De ahí que Francisco Zúñiga planteara, un año después de este sentencia, que "la jurisprudencia constitucional al consolidar la categoría de leyes de bases' modifica la 'norma de clausura' de nuestro ordenamiento jurídico. La 'norma de clausura' - prosigue-, de factura afrancesada establecía una competencia reglamentaria general y una competencia legislativa excepcional, en consonancia con el régimen presidencialista. A nuestro juicio -concluye-, el activismo del Tribunal Constitucional que modifica la 'norma de clausura' y crea pretorianamente un nuevo concepto de ley y una nueva categoría o tipo de ley, configura una verdadera mutación constitucional". Con ello precisa, además, "que las 'leyes de bases' hacen de la competencia legislativa la regla general conservando el Ejecutivo una reforzada potestad reglamentaria, innovación pretoriana de nuestro Tribunal Constitucional que de paso pretende definir la ley, arrinconando el concepto formal de ley, mediante un concepto material de ley; concepto este último no adecuado a la Constitución en la medida que coexisten en la legislación leyes generales y especiales; y una distribución de materias y de competencia legislativas compleja ${ }^{\prime \prime 37}$. Como lo veremos luego, disentimos de esta conclusión, pues precisamente plantearemos como propuesta la unidad indisoluble en nuestro sistema constitucional del concepto material y formal de ley, ya que, precisamente y algo hemos adelantado sobre el particular, la ley cumple una función jurídico material y jurídico formal.

g) En consecuencia, el dominio legal así plasmado, nos presenta un cuadro en el que resulta extremadamente difícil sostener, como en el caso francés, la existencia de una reserva de reglamento, toda vez que por medio de las leyes de bases esenciales el legislador puede extenderse más allá de las materias enumeradas en el artículo 63, operando así la congelación de rango de la ley de bases esenciales, como norma de clausura del ordenamiento jurídico chileno. Por consiguiente, para algunos autores, en cuanto a las posibilidades regulatorias del reglamento independiente, su pretendida competencia genérica quedaría, en principio, reducida a unas pocas materias que la Constitución no confía

37 ZúNIIGA URBINA, Francisco, "Leyes de Bases en la Jurisprudencia del Tribunal Constitucional: Apuntes acerca de la norma de clausura", Revista de Derecho de la Universidad Católica de Valparaíso, Vol. 23, 2002, pp. 217-218 y 235-236. 
explícitamente el legislador ${ }^{38}$ o bien, en la práctica, este tipo de reglamentos quedarían reducidos a situaciones excepcionales, por la gran competencia asignada a la ley ${ }^{39}$. Otros autores describen a la potestad reglamentaria como escuálida y difícil de imaginar ${ }^{40}$. Para Rolando Pantoja, además, al mantener el legislador su competencia de acuerdo a los criterios tradicionales ha llevado a los autores a definir la potestad reglamentaria autónoma como irrelevante e impracticable ${ }^{41}$. Sin embargo, como lo desarrollaremos más adelante, la potestad reglamentaria autónoma, posee una determinada esfera regulativa, como una manifestación de la ley en sentido material y aceptando, también, la vigencia de la noción de ley en sentido formal en nuestro ordenamiento.

En el último tiempo, y en contraposición a nuestra última conclusión, Eduardo Cordero ha planteado que, en torno al sentido y alcance del numeral vigésimo del artículo 63, la locución "Sólo son materias de ley: (...) Toda otra norma de carácter general y obligatoria (...)", "antes que establecer o determinar una materia de ley, lo que prescribe esta norma es el deber que sus preceptos han de ser generales y abstractos". En este mismo sentido, precisa que "al introducir el numeral 20 [el constituyente] establece respecto de la ley un elemento sustancial, el cual más que constituir una materia de ley es una condición que debe cumplir una norma para tener el carácter de ley". Es decir, el constituyente quiso establecer que sólo pueden ser objeto de regulación legal aquellas normas que reúnan las características de generalidad y obligatoriedad ${ }^{42}$. Por consiguiente, lo sostenido por este autor es que la ley, a partir del numeral vigésimo, puede definirse por contenidos intrínsecos, esto es, la generalidad y la obligatoriedad.

Luego, en torno a "las bases esenciales del ordenamiento jurídico", que indica el artículo $63 \mathrm{~N}^{\circ} 20$, Eduardo Cordero entiende que aquello serían "los fundamentos de lo propio o característico del derecho", y precisa que "el legislador al regular las bases esenciales de un ordenamiento jurídico debe segregar determinadas conductas y aspectos de la vida social en la medida que sean jurídicamente relevantes". Siendo "el propio legislador el que determina qué materias son jurídicamente relevantes atendiendo a los valores y condiciones sociales imperantes en una época y lugar determinado. Así, es él quien de-

38 Cazor, La sumisión, cit. nota n. 33, p. 170.

39 Bulnes, "Leyes de Base", cit. nota n. 26, p. 146.

40 Ribera, "Reserva legal", cit. nota n. 22, p. 486.

41 Pantoja Bauzá, Rolando, "La relación entre ley y reglamento en el Derecho chileno", Revista de Derecho del Consejo de Defensa del Estado, № 20, 2008, p. 30.

42 Cordero Quinzacara, Eduardo, "El sentido actual del dominio legal y la potestad reglamentaria", Revista de Derecho de la Universidad Católica de Valparaíso, vol. 32, 2009, pp. 430-431. 
termina o cumple la función de clausurar las materias de dominio legal, pues no es posible establecer a priori todas las materias que han de ser objeto de regulación jurídica"43.

En consecuencia, para este autor la referida norma establece la forma en que el legislador debe cumplir su función normativa (a través de leyes generales y abstractas) y le permite regular el más amplio espectro de materias clausurando el ámbito de la ley (bases esenciales del ordenamiento jurídico ${ }^{44}$. Por consiguiente, el dominio máximo legal se difumina y la clásica distinción entre reglamentos ejecutivos y autónomos sería una construcción artificiosa, "por tanto, la función que cumple un reglamento de ejecución respecto de un reglamento autónomo es la misma: complementar, desarrollar o detallar la regulación legal. De tal forma, la distinción que se hace entre los dos tipos de reglamentos no tiene una base real, pues ambas aparecen dominadas por el principio de la primacía de la ley sobre las normas reglamentarias". Concluye finalmente este autor, que "en nuestro ordenamiento no existe un dominio legal mínimo [o ¿máximo?], puesto que la ley es la norma que clausura las materias de reserva de ley. Así las cosas, en nuestro derecho sólo existirían reglamentos, siendo un artificio la distinción entre reglamento autónomo y de ejecución" ${ }^{\prime 4}$.

h) Por su parte, Miguel Ángel Fernández postula que el referido numeral 20, del artículo 63, a propósito de la jurisprudencia del Tribunal Constitucional, "está redactado en términos excesivamente amplios pero no tanto como para sostener que sea una norma indeterminada 'sin señalar directamente el contenido de aquello que debe ser materia de ley', ya que ese contenido es claro en cuanto a que la ley debe regular las bases esenciales del ordenamiento jurídico y ello, a diferencia de lo que se expone en la sentencia, no constituye una característica meramente formal, sino que sustantiva de la ley". Luego, señala que "la amplitud de lo preceptuado en el artículo $63 \mathrm{~N}^{\circ} 20$ de la Constitución no puede entenderse como constitutivo del principio de dominio mínimo legal, adulterando el modelo establecido en la Carta Fundamental. Al contrario, en ese precepto se define, precisamente, el contenido de la materia a legislar -cualquier asunto que sea básico en el ordenamiento jurídico-, sin que pueda leerse como que allí se autoriza a la ley para disponer acerca de cualquier asunto, aunque no sea básico, pero normándolo en lo esencial". Finalmente, dentro de este concepto de primacía de la ley, plantea Fernández "lo innecesario que resulta para el Presidente de la República acudir a su potestad autónoma cuando posee un control férreo del proceso formativo y del contenido de la

\footnotetext{
43 Cordero, "El sentido actual", cit. nota n. 42, pp. 432-433.

44 Cordero, "El sentido actual", cit. nota n. 42, p. 433.

45 Cordero, "El sentido actual", cit. nota n. 42, pp. 433-435.
} 
ley, dotando de mayor y más indiscutible legitimidad [a] la decisión adoptada por esa vía; y porque es evidente que nuestra cultura jurídica se encuentra aún fuertemente sustentada en la ley y en sus méritos, conduciéndonos siempre a privilegiar su intermediación" 46 .

i) Desde ya, se puede criticar en este ámbito a la doctrina nacional, pues el método de interpretación utilizado es, más bien, una lectura originalista de la Carta. Cuestión que genera una situación paradójica, pues si se analizan a dos autores nacionales que utilizan el mismo método interpretativo, se obtienen resultados disímiles y contradictorios. Así, por ejemplo, para Teodoro Ribera el sistema pretendido por el constituyente sería el de dominio mínimo legal, y, por su parte, Miguel Ángel Fernández, utilizando la misma metodología, postula que la intención constituyente siempre fue el establecimiento de una reserva legal máxima. Por consiguiente, cabe destacar que, sobre todo en la interpretación de la Constitución, los métodos de hermenéutica sistémica y finalista resultan trascendentales, a fin de encontrar la coherencia y armonía entre las distintas normas constitucionales y, por ende, darle una funcionalidad a la garantía de la reserva legal que esté más acorde con el principio democrático y las reglas del Estado de Derecho.

Luego, es criticable también que la doctrina mayoritaria en nuestro país genere un verdadero "estrangulamiento" sobre la potestad reglamentaria autónoma, no obstante tener un claro reconocimiento en la Carta Fundamental. En efecto, por una parte Miguel Ángel Fernández no precisa en su tesis las posibilidades regulatorias del reglamento independiente o derechamente plantea lo innecesario del mismo. Y, a su vez, Eduardo Cordero sostiene que resulta una construcción artificiosa la distinción entre reglamento autónomo y de ejecución; lo que, a nuestro parecer, no puede admitirse, especialmente en base a lo establecido en la propia Carta Fundamental, ya que, por una parte, es el propio artículo $32, \mathrm{~N}^{\circ} 6$, que identifica conceptualmente los reglamentos que regulan "aquellas materias que no sean propias del dominio legal"; y, por otra parte, es la propia reforma constitucional de 2005 que incorpora al artículo $93, N^{\circ} 16$, una hipótesis específica de control de la potestad reglamentaria autónoma, consagrándola expresamente como objeto de control y utilizando dicha terminología en el propio texto (dice la Constitución: "Resolver sobre la constitucionalidad de los decretos supremos (...) incluyendo aquellos que fueren dictados en el ejercicio de la potestad reglamentaria autónoma del Presidente de la República cuando se refieran a materias que pudieran estar

${ }^{46}$ Fernández González, Miguel Ángel, "Antecedentes históricos y jurisprudenciales acerca de la potestad reglamentaria autónoma" (Coordinadores Jaime Arancibia y José Ignacio Martínez), La primacía de la persona: Estudios en homenaje al profesor Eduardo Soto Kloss, LegalPublishing, Santiago, 2009, pp. 751-753. 
reservadas a la ley por mandato del artículo 63"), es decir, lo que antes sólo era una construcción meramente doctrinaria, la reforma constitucional lo consagra expresamente.

j) Finalmente, es posible constatar en la doctrina chilena (por ejemplo, Cordero, Fernández y Ribera), que se hace de la esencialidad -a propósito del art. $63 N^{\circ} 20-$ el único criterio funcional a fin de definir las relaciones entre ley y reglamento independiente. Particularmente, creemos poco justificado identificar todo rasgo material o de contenido en el concepto de "bases esenciales", como lo hace Cordero, con las "materias jurídicamente relevantes", lo que traería como resultado práctico una reserva total de ley en razón de dicha esencialidad (material) sin contornos, que no tendría asidero constitucional, sobre todo si consideramos también la existencia del concepto de ley en sentido formal. Por otra parte, lo esencial resulta altamente abstracto y difuso, así Ribera señala que las bases o materias básicas deben precisarse según la materia a regular, siendo su extensión e intensidad de acuerdo con la complejidad de la misma ${ }^{47}$; asimismo, luego se expresa que únicamente el legislador debe definir su propio ámbito competencial, lo que convierte la decisión legislativa en altamente contingente. Para Moraga la competencia del legislador no puede quedar a discreción de los propios órganos co-legisladores, sino que debe considerarse el marco de la Constitución que, de manera previa, ha establecido distintos parámetros de distribución organizacional de la potestad normativa general ${ }^{48}$; si bien, se refiere a la densidad normativa exigida a la ley, es decir, a la distribución vertical de potestad normativas entre ley y reglamento ejecutivo, su argumentación es aplicable, igualmente, al ámbito de materias sujetas a reserva (distribución horizontal, ley y reglamento independiente).

Del mismo modo, se debe tener presente que la reserva también se dirige contra el legislador, "impidiendo que distribuya competencias normativas sobre el núcleo esencial de la materia"49, por consiguiente, que el legislador deba definir su exclusivo ámbito competencial sería algo contrario a la propia reserva constitucional de ley. En consecuencia, como bien se ha planteado, "se debe ser muy cuidadoso al momento de argumentar interpretaciones extensivas de la reserva legal, lo que lejos de ampliar las competencias del legislador, muchas veces conducen a dificultar la necesaria actuación de la Administración" ${ }^{\prime 50}$. Igualmente, "no sería coherente plantear la tesis de los mandatos de sustancia

47 Ribera, "Reserva", cit. nota n. 22, pp. 484-485.

48 Moraga Klenner, Claudio, "La actividad formal de la Administración del Estado" (Coordinador Rolando Pantoja), Tratado de Derecho Administrativo, LegalPublishing, Santiago, 2010, p. 49.

49 CAzor, "Problemas conceptuales", cit. nota n. 21, p. 307.

${ }^{50}$ Cazor, "Problemas conceptuales", cit. nota n. 21, p. 308. 
preceptiva amplia de la reserva legal en Chile, que en la práctica hace inoperante el ejercicio de la potestad reglamentaria independiente, la cual tiene una clara consagración constitucional y sólo se vincula negativamente a la ley"51.

\section{II.2. La noción material-formal de la ley en la Constitución: ¿Una incoherencia conceptual?}

La pregunta que, necesariamente, emana de lo argumentado hasta ahora, es la siguiente: ies posible constatar en la estructura de nuestras potestades normativas, la existencia de un concepto de ley material y de ley formal? Y si es positiva la respuesta, ¿qué consecuencias traería ello en nuestro sistema constitucional?

Para responder a esta duda, hay que precisar los ámbitos del dominio legal plasmados en la Constitución. Por una parte, como ya algo hemos adelantado, a la luz del art. 63, claramente quedó configurado un dominio mínimo legal de carácter material, en donde los $\mathrm{N}^{\circ}$ s. $1^{\circ}$ a 19 de dicha disposición reservan a la ley una serie de contenidos materiales (específicos o generales), utilizando en cada caso expresiones diversas, ya sea de un modo general, al entregar sólo a la "ley" la regulación de una determinada materia sin mayor descripción del ámbito (reserva absoluta), o, ya sea de un modo específico, en donde el mandato sea preciso y consagre los elementos que la ley debe contener (reserva relativa); cuestión que ratificaría la existencia de una concepción de ley material. Por otra parte, en los casos no previstos expresamente por la Constitución, cabe aplicar el numeral 20 del artículo 63, que contiene sólo una limitación en lo relativo a la intensidad o profundidad de la regulación, pero no en cuanto a los contenidos que puede alcanzar ${ }^{52}$, cuestión que ratificaría también la existencia de una concepción de ley formal o reserva formal-material.

En efecto, como se ha dicho por la doctrina, "no puede olvidarse que el origen de esta disposición constitucional se encuentra en el indisoluble propósito de la Junta de Gobierno de equilibrar la relación de poderes entre el Presidente de la República y el Congreso Nacional, evitando por un lado la existencia de leyes casuísticas, pero por otro que la potestad reglamentaria pudiere minimizar la relevancia propia de la ley"53. Especialmente relevante en este último punto es la existencia de una "competencia traslapada eventual" ${ }^{54}$ entre la ley o

\footnotetext{
51 Cazor, "Problemas conceptuales", cit. nota n. 21, p. 309.

52 Ribera, "Reserva", cit. nota n. 22, p. 482.

53 Ribera, "Reserva legal", cit. nota n. 22, p. 21. Ver también: Ribera, "Reserva", cit. nota n. 22, pp. 471-489.

54 Ribera, "Reserva legal", cit. nota n. 22, p. 25. Ver también: RiberA, "Reserva", cit. nota n. 22, pp. 471-489.
} 
reserva formal-material (ya que existe la posibilidad de que la ley abarque, en virtud del art. $63 \mathrm{~N}^{\circ} 20$, otras materias inicialmente no previstas) y la potestad reglamentaria autónoma o independiente.

Un ejemplo de ello es lo que aconteció con el decreto supremo $N^{\circ} 81$ de 1999, que reguló el uso de la firma digital y los documentos electrónicos en la Administración del Estado, materia que -no obstante estar en parte sistematizada en dicho reglamento autónomo- fue posteriormente reglada por la ley $N^{\circ} 19.799$, sobre documentos electrónicos, firma electrónica y servicios de certificación de dicha firma, en donde precisamente en su título segundo trata acerca del uso de firmas electrónicas por los órganos del Estado. Otra muestra, es lo sucedido con la creación de la Comisión Nacional Asesora de Acreditación de Pregrado (CNAP), creada en marzo de 1999, mediante decreto supremo $N^{\circ}$ 51, del Ministerio de Educación, de ese año, posteriormente la ley $N^{\circ} 20.129$, de noviembre de 2006, que estableció un Sistema Nacional de Aseguramiento de la Calidad de la Educación Superior, constituye formalmente la Comisión Nacional de Acreditación (CNA-Chile).

Finalmente, otro ejemplo es el decreto reglamentario $\mathrm{N}^{\circ} 264$, de octubre de 2010, del Ministerio de Transportes y Telecomunicaciones, que fijó las normas complementarias del decreto supremo $\mathrm{N}^{\circ} 136$ de 2009 y "ejecuta" el inciso final del art. 15 de la Ley General de Telecomunicaciones, estableciendo un nuevo período anual de exposición pública y abierta, renovable hasta por un máximo de cinco años, dentro del cual se podrían otorgar permisos para efectuar transmisiones demostrativas del servicio de radiodifusión televisiva de libre recepción con tecnología digital o renovar las existentes. Analizado el decreto reglamentario $N^{\circ} 264$, a la luz del inciso final del art. 15 de la Ley General de Telecomunicaciones, sin duda generó un exceso regulativo de la norma que "ejecutaba", y la explicación de ello habría que circunscribirla al hecho de que "la Ley General de Telecomunicaciones, al tratarse de una ley marco -o de bases esenciales- y con un claro contenido técnico, cuyo apoderamiento normativo se plasma dentro de un campo material indeterminado, que la apertura del artículo $63 \mathrm{~N}^{\circ} 20$ la plantea dentro del concepto de reserva formal de ley, y que no agotaría otras posibilidades de regulación, de ahí que exista un espacio para que innove la potestad reglamentaria presidencial, especialmente la potestad reglamentaria autónoma" ${ }^{\prime 55}$. Finalmente hay que agregar que, en esta temática de la televisión digital, su regulación todavía está en discusión en el Congreso Nacional, en donde se plantea nuevamente la situación de que un decreto supremo -no de estricta ejecución, sino más bien independiente-, regule una materia antes de ser normada por una ley.

${ }_{55}$ Cazor Aliste, Kamel, "Regulación reglamentaria v/s regulación legislativa", Revista de Derecho Universidad Católica del Norte, año 18, n. 2, 2011, pp. 396. 
En consecuencia y a mayor abundamiento, "si entendemos que en nuestro sistema constitucional hay cabida a la reserva formal de ley del modo antes explicado, la ley en potencia podría regular una materia que no está en el campo determinado del art. 63, y mientras no existe tal apoderamiento legislativo podría ser normada por la potestad reglamentaria autónoma, cuyo resultado normativo son en estricto sentido leyes materiales. Por ello, se podría concluir que el sistema de reserva legal en nuestro país (del art. 63), no necesariamente significa que éste haya sido formulado como una exigencia exclusiva para las leyes materiales, pues debe subsistir con otra esfera regulativa de leyes materiales, como son los reglamentos independientes. De ahí que -se concluye- la reserva en nuestro sistema de fuentes no afecta toda la perspectiva de la potestad normadora de la Administración" ${ }^{\prime 56}$. Por ello que, en nuestro sistema constitucional, es posible constatar como unidad indisoluble la existencia de leyes materiales y leyes formales, cuya funcionalidad debe explicarse en los términos ya descritos, cuestión que, como se verá a continuación, no ha estado exenta de problemas, especialmente, cuando se ha pretendido una comprensión teórica del mismo.

Por esta razón tendremos que buscar auxilio en las doctrinas comparadas que indagan en los orígenes de los sistemas de potestades normativas, ya que nuestra fórmula, que configura las esferas de tales potestades, no es para nada original, sino más bien es un reflejo imperfecto de aquellas doctrinas (principalmente francesa y alemana), las que ha tratado de adecuar -con poco éxito hasta ahora- a las realidades constitucionales en vigor de su tiempo, primero, de la Carta de 1925 y, luego, de la Carta de 1980.

Un punto básico para comenzar a desarrollar nuestra argumentación, es abordar la influencia de los conceptos de ley formal, material y general, en la configuración del principio de legalidad y de la reserva de ley. Entre estos conceptos ha habido interrelaciones, confusiones e incluso identificaciones ${ }^{57}$, de los cuales nuestro sistema constitucional no ha estado ajeno. De ahí que, desde esta perspectiva, haremos referencia al principio de legalidad y al principio de reserva legal.

El principio de legalidad cabe entenderlo dentro del concepto de ley general (primacía de la ley, identificando Derecho con la ley, poseyendo ésta supremacía sobre las demás Fuentes del Derecho, reguladora de las condiciones de producción de las demás normas y definidora de los términos de su articulación; es decir, actúa como mecanismo garantista, de subordinación de todos los poderes públicos ${ }^{58}$ ), como también dentro del concepto de ley formal y material (aquí

\footnotetext{
56 CAzOr, "Regulación", cit. nota n. 55, pp. 396-397.

57 De CaBo, Sobre el, cit. nota n. 4, p. 60.

58 De Cabo, Sobre el, cit. nota n. 4, p. 61.
} 
se "comprenden el que es el ámbito más común al que se remite el significado del principio de legalidad: el de la relación entre Administración (actuación administrativa) y ley" $\left.{ }^{\prime \prime 5}\right)$. Por ello, como indica De Cabo, dentro de este ámbito pueden distinguirse tres posiciones:

a) En primer término, "el principio de legalidad entendido, justamente, como expresión global de la relación entre Estado y ley (...) incluye dos aspectos: la primacía de la ley como preferencia jurídica sobre cualquier otra manifestación estatal y la reserva de ley que añade al marco y límite necesario que la ley supone para la Administración al ser fundamento de su actuación evitando su autonomía (Starck y Jesch)"

b) En segundo término, "el principio de legalidad entendido como principio de juridicidad" se vincula con la necesaria conexión existente entre Estado y Derecho, es decir, los órganos del Estado están sometidos al ordenamiento jurídico ${ }^{61}$. Entendido así, el principio de juridicidad "es un concepto genérico, más amplio que el de legalidad ya que incluye al principio de legalidad como una juridicidad calificada, que opera, este último, cuando la fuente jurídica que sirve de fundamento a los poderes constituidos es la ley" ${ }^{\prime \prime 2}$. Sobre el particular es importante resaltar que, como señala Adolf Merkl, el principio de legalidad presupone el principio de juridicidad, pero no necesariamente a la inversa ${ }^{63}$. A medida que se desarrolla el Estado de Derecho, el principio de juridicidad se modula en un doble sentido: no sólo implica la prohibición de toda actuación antijurídica (actuación conforme a Derecho), sino que también determina que no basta cualquier norma sino la que reúna determinados caracteres ${ }^{64}$.

c) En tercer término, el principio de legalidad debe ser entendido "en el sentido más habitual y propio de sometimiento de la Administración en su integridad, es decir, no sólo cuando opera concretamente, mediante actos administrativos, sino cuando desarrolla su actividad normativa, a la ley en sentido estricto. $Y$ es aquí donde se proyectan los conceptos de ley formal y ley material, pues ha sido basándose en ellos como se ha articulado la discusión clásica sobre aquel tipo de sometimiento" ${ }^{\prime 65}$.

59 De Caвo, Sobre el, cit. nota n. 4, p. 63.

60 De Cabo, Sobre el, cit. nota n. 4, p. 63.

61 De Caвo, Sobre el, cit. nota n. 4, p. 63.

62 Cazor, La sumisión, cit. nota n. 33, p. 58.

63 MerkL, Adolf, Teoría General del Derecho Administrativo, 1953, Madrid, Editorial Revista de Derecho Privado, Madrid, 1953, p. 215.

64 De CaBo, Sobre el, cit. nota n. 4, p. 63.

65 De CABO, Sobre el, cit. nota n. 4, p. 63. 
c.1) Si se parte del concepto de ley material, en cuanto el Ejecutivo tenga una atribución originaria (como es, por ejemplo, el carácter originario de la potestad reglamentaria en Chile, arts. 24 y $32 \mathrm{~N}^{\circ} 6$ de la Carta), implica que el Ejecutivo puede actuar siempre que no se trate de materias (libertad y propiedad) que exigen una regulación legal; razón por la cual, si la Administración opera en el ámbito material propio de la ley, la vinculación de la Administración a ésta es necesariamente positiva (por ello, los reglamentos no podrían ser independientes); en cambio, fuera de dicha esfera, la vinculación de la Administración es puramente negativa, basta con no violar la ley y por tanto caben las disposiciones independientes de la Administración (...) Por consiguiente, la afirmación del carácter originario de la potestad reglamentaria implicaría aceptar este concepto y, coherentemente, sería incompatible con el concepto formal de ley ${ }^{66}$.

c.2) Por el contrario, "si se parte del concepto de ley formal, se sostiene que dada la inexistencia de límites de la ley, que, en cuanto soberana puede regular todas las materias, la Administración no puede desarrollar su actividad normativa sino en el marco previo establecido por una ley. La vinculación es, pues, siempre positiva y en ningún caso caben los reglamentos independientes" (...) La cuestión no depende por tanto de la materia sino de que el legislador es "original" y el Ejecutivo es "derivado"67.

Si trasladamos esta argumentación a la realidad constitucional nacional, debemos concluir que es plenamente aplicable la tesis de que el carácter originario de la potestad reglamentaria tendría su fundamento en el concepto de ley en sentido material. Se debe precisar, igualmente, que en el caso chileno la originalidad del legislador, que no sólo adhiere al concepto de ley material sino también al concepto de ley formal, debe compatibilizarse, vía art. 63 $N^{\circ} 20$, con la originalidad del Ejecutivo cuando ejerce su potestad reglamentaria autónoma, como vinculación negativa a la ley. De ahí la singularidad de nuestro sistema constitucional, que resulta difícil comprender.

Abordando ahora la reserva legal, hay que partir de la premisa de que ésta posee una clara "determinación constitucional que impone la regulación por ley de ciertas materias, [es decir] supone inicialmente una concepción material de ley y, consiguientemente, es incompatible con un concepto formal de ley que, en cuanto expresión de la voluntad soberana, puede regularlo todo ${ }^{\prime \prime 68}$. Para entender esta aseveración, hay que adentrarse brevemente en la perspectiva originaria de esta institución y en el sustento doctrinario actual que la respalda.

66 De CaBO, Sobre el, cit. nota n. 4, p. 64.

67 De CABO, Sobre el, cit. nota n. 4, p. 64.

68 De Cabo, Sobre el, cit. nota n. 4, p. 65. 
Teniendo presente que el origen de la reserva legal tuvo su fuente principal en Alemania, a propósito de la escisión del concepto de ley, en su perspectiva material (principio representativo) y formal (principio monárquico), estableciendo un ámbito en el que especialmente debía intervenir el principio representativo, resolviendo un problema político (ley de presupuesto) con una solución técnica basada en el orden jurídico (reserva legal) ${ }^{69}$. Este es el objetivo que está presente en la construcción de Paul Laband sobre la ley material (a partir del conocido incidente histórico de rechazo por el Parlamento del presupuesto que pretendía financiar la reforma del ejército prusiano); sin embargo, este autor utiliza los contenidos revolucionarios franceses, eso sí, adaptándolos a la realidad de su país, con fines contrarios a los que originalmente se formularon, esto es, con la finalidad política de asegurar el predominio del principio monárquico sobre el representativo, utilizando esta construcción para convertirla en base para la determinación de competencias, a fin de definir la ley como material en cuanto la identifica con la "norma jurídica", con la "regla de Derecho", en donde uno de los elementos de esa relación jurídica tiene que ser el ciudadano, de ahí que la regla de Derecho tenga como único contenido el que se refiere o afecta a lo que constituye su esfera jurídica o, lo que es lo mismo, la libertad y la propiedad; generando como consecuencia que la ley material se desvincula de la forma a través de la cual surge y, por tanto, de la representación popular ${ }^{70}$.

De ahí que Carré de Malberg, frente a la tesis de Laband, se colocó en una relación dialéctica con el pensamiento constitucional alemán, en cuanto contraponía a la doctrina constitucional de ese país el pensamiento constitucional republicano francés, ya "que Carré estimaba que en el origen de la evolución político-constitucional francesa se encontraba también el origen del Derecho constitucional moderno (...) [y] la apelación de Carré a los principios de la Revolución Francesa, y concretamente al representado por el art. $3^{\circ}$ de la Declaración de Derechos del Hombre como fundamento del Derecho constitucional moderno, suponía un completo cambio de enfoque respecto de la dogmática alemana"71.

Además, Carré, al analizar el art. $1^{\circ}$ de la Ley constitucional de 1875 y de acuerdo a su literalidad, concibe la ley como expresión del Poder Legislativo, solamente como la obra del Parlamento, por ende, la ley no se define por su generalidad ni por su objeto, y no cabe, dentro de esta perspectiva, una concepción material de la ley como la elaborada por la doctrina alemana (esto es, la ley definida por versar sobre objetos determinados). Y, como expresa

69 De CaBO, Sobre el, cit. nota n. 4, p. 65.

70 De Cabo, Sobre el, cit. nota n. 4, pp. 37, 38, 39 y 41.

71 López Guerra, Carré, cit. nota n. 15, pp. 10 y 11. 
López Guerra, "no hay pues un ámbito exento a la superioridad de la ley (...) Frente a la doctrina alemana, que atribuía al Poder Ejecutivo un área propia de actuación normativa (sobre objetos "no jurídicos" referidos a la organización y actividad administrativa), de la Constitución republicana se desprende que toda la potestad normativa del Ejecutivo está sometida a la ley, y sólo de ella obtiene su legitimidad" (...) esta posición -prosigue López- viene a representar para Carré no sólo la negación de la validez en el ordenamiento constitucional del dualismo Rey-Parlamento, sino también para rechazar la Stufentheorie que representa la doctrina kelseniana (...) La última justificación del sistema normativo no viene de la norma hipotética fundamental de Kelsen, sino de la expresión de la voluntad general como razón final del ordenamiento"72. Así, la voluntad general, canalizada a través de la ley, aparece como la última fuente de poder (como refleja el art. $6^{\circ}$ de la Declaración de 1789) y legitimidad de todo el sistema ${ }^{73}$. En definitiva, Carré adhiere a la concepción formal de ley, planteando, en consecuencia, que no existe una diferenciación entre leyes materiales y leyes formales, y que la Constitución no ha repartido las materias entre la ley y el reglamento y, por ende, es el Parlamento quien fija el ámbito de los reglamentos.

Otro enfoque de la doctrina francesa que revela el concepto de ley es el desarrollado por Léon Duguit, de mucha influencia, en su tiempo, en la literatura nacional del Derecho público. En efecto, Duguit al abordar el concepto de ley, acentúa su contenido material, con la característica de ser una norma general y abstracta; de ahí que, para este autor, los reglamentos tienen también materialmente el carácter de leyes y deben ser distinguidos de los actos administrativos, con ello la diferencia entre ley y reglamento no radica en su contenido sino en su forma (por ello, tiene el mérito de poner de manifiesto los límites materiales y formales del Poder Legislativo $)^{74}$. Citando textualmente a Duguit, expresa sobre el particular que: "Desde el punto de vista material el principio de legalidad consiste en lo siguiente: en un Estado de Derecho ninguna autoridad puede adoptar una decisión individual sino es dentro de los límites fijados por una disposición general, es decir, por una ley en sentido material" ${ }^{\prime 75}$. Por otro lado, prosigue este autor, "en todas partes se admite, en grados diversos, que hay ciertas disposiciones de carácter general que pueden ser dictadas por el gobierno. Dicho en otros términos - prosigue-, el gobierno tiene a menudo un poder Ilamado reglamentario, es decir, capacidad para dictar

72 López GuerRA, Carré, cit. nota n. 15, pp. 13-14.

73 López Guerra, Carré, cit. nota n. 15, p. 15.

74 Baño León, Los límites, cit. nota n. 19, pp. 63-64.

75 Duguit, Léon, Lecciones de Derecho público general, Marcial Pons, Madrid, 2011, p. 180. 
reglamentos que son leyes en sentido material. Es evidente que el gobierno no puede hacer reglamentos violando la ley. Pero al mismo tiempo el gobierno, en medida variable según los países, puede dictar verdaderas leyes en sentido material y de esta manera el parlamento no hace todas las leyes. Hay leyes -concluye- que son elaboradas por el gobierno" ${ }^{\prime 76}$. Interesante conclusión, de mucha importancia para comprender el concepto de ley que adoptó nuestro sistema constitucional.

Ahora bien, en principio, desaparecida la circunstancia histórica en Alemania, que dio origen a la reserva legal y muchas veces incompatible, como ya lo hemos explicado, con los sistemas constitucionales sustentados en el concepto formal de ley, parecía que la reserva se había quedado sin fundamento. Sin embargo, en la actualidad se justifica en base a dos argumentos: el principio democrático y los supuestos técnicos-competenciales de los órganos estatales, todo lo cual, en último término, se basa en una perspectiva "orgánica", tributaria todavía de lo que puede llamarse "lógica" de la ley en sentido formal, que, esencialmente, posee un entendimiento subjetivista y voluntarista del Derecho, de raíz privatista. De ahí que se deba superar esta última perspectiva mediante una concepción más objetivista y propia del Derecho público, enfrentando las contradicciones básicas del constitucionalismo actual, entre, por una parte, la estabilidad y vocación de permanencia, y, por otra parte, las exigencias de cambio y flexibilidad propias de los tiempos actuales ${ }^{77}$.

Dentro de esta perspectiva, se plantea un nuevo garantismo constitucional, en donde se entiende "a la reserva de ley como un mecanismo garantista jurídico-constitucional y que, por tanto, y junto a la democraticidad inseparable de cualquier concepto de ley (...) pone el acento en la racionalidad y objetividad del Estado de Derecho y de una de sus categorías centrales como es la ley. En este sentido, la reserva de ley significaría la exigencia de que las materias reservadas deberían ser reguladas por una norma que (además de por su origen) se defina por sus caracteres objetivos; el garantismo, pues, procedería de esos 'caracteres objetivos' que reúne la ley como puede ser el de la generalidad (...) Se considera, pues, a la reserva de ley como un eficaz medio de revalorización y defensa tanto de la democracia como del Estado de Derecho"178.

Tal ampliación de la reserva legal ha acentuado, para cierto sector de la doctrina, la problemática de su relación con el principio de legalidad y con la potestad reglamentaria; expresado de otro modo, "bajo el término 'reserva de ley', se esconden realmente dos significados distintos, uno relativo a toda la

76 Duguit, Lecciones, cit. nota n. 75, p. 184.

77 De Caвo, Sobre el, cit. nota n. 4, pp. 65-67.

78 De Caвo, Sobre el, cit. nota n. 4, pp. 68-69. 
"Problemas teóricos en torno a las potestades normativas y la necesaria redefinición de la reserva legal en el Estado constitucional chileno"

actuación administrativa y otro sólo a su potestad reglamentaria, de los que el primero encaja con lo que nosotros hemos situado en el principio de legalidad"79. De ahí que hagamos una breve mención a estos dos conceptos vinculados con la reserva de ley:

a) En primer término, se manifiesta, tanto en la teoría como en la práctica, una verdadera maraña o confusión entre reserva de ley y principio de legalidad (sobre todo cuando se plantea la relación entre Administración y ley, o dentro del contexto del principio de legalidad en materia penal| $\left.{ }^{80}\right)$, es decir, estamos frente a conceptos no del todo depurados, "por lo que es conveniente extremar el rigor de su utilización" ${ }^{\prime 21}$. Frente a esta duda, se debe necesariamente responder que no cabe identificar o confundir tales conceptos, "porque mientras el principio de legalidad supone la subordinación del Ejecutivo al Legislativo, la reserva no sólo es eso sino que el Ejecutivo no puede entrar, a través de sus disposiciones generales, en lo materialmente reservado por la Constitución al Legislativo" ${ }^{\prime 2}$. Por ello es que ciertos autores postulan la inexorabilidad de la reserva legal, ya que el papel que se le encomienda no se cubre con el princi-

\footnotetext{
79 Rebollo Puig, Manuel, "Juridicidad, legalidad y reserva de ley como límites a la potestad reglamentaria del Gobierno", Revista de Administración Pública, №125, 1991, p. 65.

80 Sobre el particular, resulta relevante citar a Juan Fernando López Aguilar, que parte del supuesto de que el sistema español ha carecido de una auténtica ciencia iusconstitucional sobre la teoría de la ley, y como proyección de esta ausencia, "el principio de legalidad no puede por menos que presentar acepciones y matices diversificados en función de las distintas raíces -dogmáticas e ideológicas- de las distintas disciplinas de nuestro programa académico (...) Resulta, de esta manera, del todo revelador el que la idea de reserva constitucional de ley en la materia penal haya tendido a interpretarse como 'competencia objetiva' de los tratadistas penales, aun cuando sea evidente que la óptica y el objetivo delimitado de esta ciencia imponen sesgos distintivos respecto a los que se plantean, en modo más acusado, desde la perspectiva iusconstitucional" ("La reserva constitucional de ley en materia penal", Revista Española de Derecho Constitucional, №33, 1991, pp. 110-111). Así, por ejemplo, si observamos el tratamiento de esta materia por la doctrina nacional, Juan Bustos Ramírez y Hernán Hormazábal Malarée, se indica que "el principio de legalidad tiene una doble función. Una función incompleta de validez material de la norma penal al dar cumplimiento a las exigencias de exclusión de la arbitrariedad, y una función de dar validez formal a la norma penal", y, posteriormente, al tratar la reserva de ley, como fuente formal, se indica que "la ley es la fuente del Derecho penal por excelencia, excluyéndose los reglamentos, la costumbre y la jurisprudencia" (Lecciones de Derecho Penal chileno, vol. I, Librotecnia, Santiago, 2012, pp. 128 y 175). Es decir, en la esfera de nuestra doctrina penal, se confunden y no existe una distinción clara entre principio de legalidad y reserva legal, en cuya propuesta se trata, al parecer, de dar una respuesta al desafío en el que desempeñaban un papel protagónico las concepciones material y formal de ley. De ahí que, al contrario del Derecho penal, el Derecho constitucional plantee la exigencia de la reserva legal, ya que el papel que cumple no se cubre con el principio de legalidad, que es solo un límite, mientras que la reserva enlaza además una exigencia reguladora. Sin duda se trata de una temática cuyo tratamiento está aún pendiente en nuestra literatura.

81 Rebollo, "Juridicidad", cit. nota n. 79, p. 65.

82 De Cabo, Sobre el, cit. nota n. 4, p. 69.
} 
pio de legalidad, que es sólo un límite, mientras que la reserva enlaza además una exigencia reguladora. En este punto, conviene citar nuevamente a Manuel Rebollo, quien sintetiza muy bien esta problemática desde la perspectiva de la actuación de la Administración: "El principio de legalidad, como explicábamos, coloca a la Administración en un lugar determinado en el conjunto de las funciones estatales y, particularmente, respecto a la ley. Por el contrario -prosigue-, la reserva constitucional de ley, tal y como es entendida en nuestro Derecho, entraña únicamente, al menos de manera directa, una regla sobre fuentes del Derecho que, consistente en atribuir en exclusiva determinadas competencias normativas al Poder Legislativo, en establecer que determinadas regulaciones sólo pueden hacerse por ley, impide a la Administración el ejercicio de su potestad reglamentaria, pero sin afectar, en principio, a sus otras posibles manifestaciones (...)-concluyendo- que las reservas constitucionales de ley no tienen por función esencial limitar en general la actuación administrativa, sino sólo la reglamentaria (...) -en consecuencia- los efectos sobre la potestad reglamentaria de la existencia de una reserva constitucional de ley y del principio de legalidad son distintos" ${ }^{\prime \prime 3}$.

b) En segundo término y enlazado con lo que se indicó en el punto anterior, también se plantea la cuestión en torno a la reserva legal y la atribución constitucional de la potestad reglamentaria, en donde se da una relación -en la materia reservada- entre la ley y el reglamento. Frente a este asunto y citando nuevamente a Carlos de Cabo, se debe inevitablemente responder que "en este caso la exigencia de ley previa es sólo un requisito pero no la causa de la potestad reglamentaria que debe ser respetada, por lo que la ley no es libre en la materia. Se considera así que no hay simple ejecución de una norma por otra, sino colaboración entre ellas, lo que supone un ámbito de discrecionalidad para la Administración. A partir de aquí, se distingue, por razón de la materia reservada, entre reserva de derechos y libertades y reserva en otros campos, entendiéndose que en éstos la discrecionalidad de la Administración es mayor hasta el punto de que la ley debe determinar únicamente organización, procedimiento o fines a conseguir por el Ejecutivo más que hacer ella misma la regulación de la materia" ${ }^{\prime 4}$.

En consecuencia, ¿ es la ley en sentido estricto la que debe regular la materia reservada? Para responder esta interrogante hay que partir de un entendimiento constitucional de la reserva legal. En efecto, precisamente tal entendimiento configura la reserva como una obligación del Parlamento (planteada "contra el legislador", sobre todo en materia de derechos fundamentales, es decir, teniendo

83 Rebollo, "Juridicidad", cit. nota n. 79, pp. 124-125.

${ }^{84} \mathrm{De}$ CABO, Sobre el, cit. nota n. 4, p. 70. 
presente este especial contenido regulativo, la reserva de ley no afecta a las relaciones especiales de sujeción, sino que sólo afecta a las relaciones generales de sujeción, utilizando la terminología de Otto Mayer ${ }^{85}$ ) "de regular ciertas materias mediante un tipo de norma especificada por su estructura objetiva (...) lo que permite a la reserva configurarse como un importante mecanismo de revalorización del garantismo que incorpora el Principio democrático y el Estado de Derecho" ${ }^{\prime 86}$. Que no es otra cosa, en última instancia, que plantear la vital relación, dentro del Derecho constitucional, entre Democracia y Constitución, cuyas implicancias son de trascendental importancia dentro del sistema de Fuentes del Derecho.

Pese a que en la actualidad la primacía absoluta de la ley ha dejado lugar a la supremacía de la Constitución y, por ende, a la existencia de una jurisdicción constitucional que dispone de un considerable derecho de control, la ley sigue patentizando, sino ya el primero, sí el puesto central del orden jurídico, en cuanto expresión de la voluntad general ${ }^{87}$. Como indica Luis Villacorta reflexionando a la luz del ordenamiento español, "está así fuera de toda duda su superioridad y primacía "relativa" [de la ley], debido a ser la suprema manifestación de la voluntad del Estado en el marco de la Constitución y, en consecuencia, su primacía frente a los actos normativos -y no normativos- de la Administración pública, y ello por virtud no solo del principio de legalidad sino también del principio de jerarquía normativa contenida en el mencionado artículo 9.3 de la C. E., expresión a su vez del Principio Democrático" ${ }^{\prime 88}$.

Incluso, tal perspectiva de la reserva, y por ende de primacía de la ley, ha ganado terreno en sistemas constitucionales, como el francés de 1958, en donde la reserva legal ha debido convivir junto a la esfera regulativa que se le reserva al reglamento. En efecto, como indica Baño León, "las dos figuras que definían la nueva figura constitucional [de 1958] han desaparecido en virtud de la jurisprudencia sobre la que han pesado no sólo la concepción tradicional republicana de la ley, sino, sobre todo, la imposibilidad práctica -sobre la que

\footnotetext{
${ }^{85}$ En efecto, partiendo de la teoría formulada por Otto Mayer, de las relaciones generales y especiales de sujeción, se ha dicho lo siguiente: "La reserva sólo afecta a las relaciones generales de sujeción, a las que se entablan entre el Estado y los ciudadanos en cuanto tales; lo que la reserva protege es el ámbito material de la propiedad y la libertad de los ciudadanos o aquellas medidas organizativas que son instrumentales de esas garantías (el proceso judicial o la organización de los Tribunales de justicia, por ejemplo). Pero cuando el ciudadano está en una relación especial de sujeción o de deber con el Estado, cuando forma parte de su aparato organizativo (funcionario) o tiene relaciones especiales con él (reclusos, soldados, escolares, etc.), entonces no opera la reserva legal" (BAÑo LEÓn, Los límites, cit. nota n. 19, p. 47).

${ }^{86}$ De CABO, Sobre el, cit. nota n. 4, p. 71.

87 Pérez Royo, Javier, Las fuentes del Derecho, Tecnos, Madrid, 2007, pp. 17 y 91.

${ }^{88}$ Villacorta Mancebo, Luis, Reserva de ley y Constitución, Editorial Dykinson, Madrid, 1994, p. 26.
} 
tanto insistiera Carré de Malberg- de distinguir materialmente la ley del reglamento (...) el Consejo Constitucional ha interpretado que la ley puede abarcar ámbitos reservados constitucionalmente al reglamento, sin que ello determine necesariamente su inconstitucionalidad formal"89. En definitiva, "la definición material de ley, ha quedado prácticamente desterrada al desaparecer todo límite constitucional a la intervención de ésta en el dominio reglamentario; y el reparto normativo entre la ley y el reglamento se organiza, en suma, sobre la base tradicional de reservar a la primera la regulación de los aspectos fundamentales y al segundo su ejecución o desarrollo ${ }^{\prime \prime 90}$. Es decir, en el desarrollo actual el sistema francés se plantea una mixtura entre el concepto material y el concepto formal de ley, muy similar al que podemos también vislumbrar en nuestro ordenamiento constitucional.

De lo expuesto hasta ahora podemos deducir cuatro importantes consecuencias en nuestra propuesta argumentativa:

a) Que, como primer asunto, en nuestro sistema constitucional no existe una reserva negativa de ley, ya que, en el ámbito de la reserva material-formal en vigor, coexiste una verdadera "laguna material" de normativización, que se traduce en un problema de determinación de las "realidades susceptibles de regulación" ${ }^{\prime \prime 1}$.

b) En segundo lugar, tampoco existe en estricto sentido una reserva material de reglamento, como sí es posible vislumbrar en Francia, "en donde, por ejemplo, la ley posee una competencia excepcional, o sea, de atribución, y el reglamento, además de su reserva (en el sentido de articular la Constitución unos mecanismos para el caso de que la potestad reglamentaria pretenda alterar un precepto materialmente reglamentario incluido en una norma legal), disfruta de una cláusula general de competencia"92; sin embargo, como ya lo hemos visto, en la actualidad estos criterios generales no se vislumbran con la claridad que el constituyente francés los estableció en su texto primitivo, especialmente lo referente a la excepcionalidad de la ley, al igual como acontece en nuestro país.

c) Como tercer asunto, hay que precisar que si bien las características de generalidad y abstracción de la ley, poseen-según la tradición del constituciona-

\footnotetext{
89 Baño León, Los límites, cit. nota n. 19, p. 70.

90 Pascual Medrano, Amelia, "La ley y el reglamento en el Derecho Constitucional francés", Revista de Estudios Políticos (Nueva Época), Núm. 106, 1999, p. 228. En este mismo sentido, ver también: Tremeau, Jérôme, La Réserve de loi. Compétence Législative et Constitution, Presses Universitaires D’Aix-Marsielle, Aix-en-Provence, 1997, pp. 209 et suivant.

91 CAZOR Aliste, Kamel, "¿Reserva material del reglamento en el sistema constitucional chileno? Comentario a propósito de la sentencia del Tribunal Constitucional Rol №591/2006", Revista de Derecho, Universidad Católica de Valparaíso, XXXVII Jornadas de Derecho Público, 2007, p. 81.

${ }_{92}$ CAZOR, “¿Reserva”, cit. nota n. 91, p. 84.
} 
"Problemas teóricos en torno a las potestades normativas y la necesaria redefinición de la reserva legal en el Estado constitucional chileno"

lismo liberal del siglo XVIII- un claro contenido material, otra cosa muy distinta es confundirla con el objeto sustancial normado, que en nuestro sistema posee una clara indeterminación respecto a las realidades materiales susceptibles de regulación. Ya que el criterio de generalidad instaurado por el constituyente chileno, a fin de superar las leyes particulares o casuísticas, debe ser comprendido en el estricto sentido que ha precisado la doctrina autorizada, esto es, aquella que indica que "la generalidad es aquella cualidad de la ley en virtud de la cual sus destinatarios están genéricamente determinados [sujetos], y las conductas a las que se aplica [supuestos], abstractamente consideradas" ${ }^{\prime \prime 93}$, definición que, además, es conexa con el actual proceso de materialización incompleto de la ley, en donde, resulta más propio optar por un concepto material-formal de ley, pues tampoco el legislador chileno ha perdido su capacidad normativa ilimitada. Todo lo cual, si es bien entendido conceptualmente, no plantea una incoherencia por la subsistencia de ambas nociones de ley.

d) Finalmente, creemos que es posible constatar en nuestro ordenamiento constitucional, por un lado, las nociones de ley que se definieron, por su contenido material, como norma general y abstracta (posición liberal-siglo XVIII) o como norma jurídica (regla de Derecho) que afecta derechos de los particulares (posición en las monarquías constitucionales-siglo XIX); y, por otro lado, es posible también comprobar, la noción de la ley que es por completo independiente del objeto material de de su regulación (siglo XX), es decir, se trata de una concepción formal de ley. Ambos conceptos de ley, como lo hemos visto, responderían a un orden de ideas diferentes; especialmente relevante sería la primera noción (de las monarquías constitucionales del siglo XIX, especialmente en Alemania), pues a partir de ella surge la distinción dualista entre leyes materiales y leyes formales, que, según Carré, sería artificiosa, a la luz de la noción de ley que no se reserva únicamente al carácter general de la misma, como tampoco a una norma que incida en los derechos de los particulares, ya que la capacidad regulatoria de la ley era totalmente independiente al objeto material que podía regular ${ }^{94}$. De la misma forma, como ya lo analizamos, a diferencia de Carré, Léon Duguit al abordar el concepto de ley acentúa su contenido material, con la característica de ser una norma general y abstracta; de ahí que, para este autor, los reglamentos tienen también materialmente el carácter de leyes, con ello la diferencia entre ley y reglamento no radica en su contenido sino en su forma, abriendo, en consecuencia, la posibilidad de dictar reglamentos que son leyes en sentido material.

93 De CABO, Sobre el, cit. nota n. 4, p. 47.

94 Carré de Malberg, Raymond, La ley, expresión de la voluntad general. Estudio sobre el concepto de ley en la Constitución de 1875, Marcial Pons, Madrid, 2011, pp. 31-37. 


\section{Las tesis de Carlos de Cabo frente a las transformaciones ACTUALES DE LA LEY: AlGunAS PROPUESTAS CONCLUSIVAS EN TORNO A LA NECESARIA REDEFINICIÓN DE LA RESERVA LEGAL EN CHILE}

Para hacer algunas propuestas de redefinición de la reserva legal en nuestro país, haremos referencia a las transformaciones actuales de la ley y los efectos que ello genera en su conceptualización, utilizando para ello las interesantes tesis desarrolladas por el profesor español Carlos de Cabo Martín.

En efecto, plantea este autor el estudio del Derecho desde una perspectiva científica, lo que supone un examen sistemático y que aspira a un conocimiento explicativo. De ahí que ese análisis científico del Derecho exija tener en cuenta, junto a las determinaciones internas, las determinaciones externas, así como sus interacciones (cuestiones de mucha relevancia para la comprensión del sistema chileno). Se diferencia así el saber científico del técnico, propio del "operador" jurídico. La cuestión de las Fuentes es particularmente atractiva para este enfoque científico, pues sólo se hacía referencia a elementos internos del ordenamiento, como un exponente paradigmático de la autonomía del Derecho; pero, en este enfoque propuesto, no sólo no es posible mantener la autonomía del Derecho, sino que precisamente es uno de aquellos en los que más clara, intensa, próxima y rápidamente se acusan las determinaciones externas. Todo ello le da un mayor valor explicativo a los mecanismos de producción y reproducción del Derecho. Utilizando como paradigma externo el constitucionalismo del Estado social ${ }^{95}$.

En este contexto, frente a la expresión tan poco afortunada y gastada como la de "crisis de la ley"96, su problemática demanda nuevas reflexiones, que ha sido incentivado por "el paso del capitalismo liberal al monopolístico", y "las nuevas relaciones Estado-sociedad que traducen las nuevas demandas del sistema socio-económico (lo que determinó el surgimiento del Estado social) y la nueva configuración e instrumentación del Estado" ${ }^{\prime \prime 7}$.

Esto se traduce, siguiendo a De Cabo, en causas externas al ordenamiento jurídico y otras causas internas.

a) Causas externas: El pensamiento posmoderno implica la crisis del pensamiento fuerte en cuanto pensamiento global (ruptura de los supuestos cultu-

95 De Cabo, Sobre el, cit. nota n. 4, pp. 9-10.

96 Sobre el particular, en la doctrina nacional Miriam Henríquez Viñas, ha asumido la tesis de que la "noción de ley está en crisis (...) Lo dicho -indica además- no significa que la ley haya desaparecido en el Sistema de Fuentes del Derecho; por el contrario, sigue siendo la categoría central del Estado Constitucional y democrático de Derecho. La crisis de la ley -concluye- ha supuesto esencialmente la degradación de aquélla, que ha cedido a la Constitución su carácter de fundamento de toda la construcción normativa" (Las fuentes formales del Derecho, LegalPublishing, Santiago, 2009, pp. 22 y 24).

97 De CABO, Sobre el, cit. nota n. 4, p. 73. 
rales). Se trata de la quiebra de la Razón configurada desde la Ilustración, de su abstracción, generalidad y objetividad y su sustitución, por lo concreto, lo empírico y lo subjetivo. Lo que se vincula con el fenómeno de fragmentación jurídica y de desformalización, con progresiva pérdida de relevancia de los caracteres propios de las Fuentes formales del Derecho estatal (supremacía o aplicación general), deslegalización y deterioro de las ideas de código. Por otra parte, la ley ha dejado de ser el instrumento básico de regulación de las sociedades modernas, especialmente por su carácter consensual, ya que las sociedades actuales son mucho menos "abiertas" y "pluralistas" de lo que sus notables teóricos presentaban en violento contraste con las sociedades "cerradas". La escasa "apertura" y el mínimo "pluralismo", se pone de manifiesto en la proximidad de las opciones económico-sociales y políticas que configuran un fondo de "consenso" en lo fundamental, que procede no ya de la subjetiva "voluntad conciliadora" de las partes, sino de su objetiva coincidencia en los puntos básicos. Con ello, las tradicionales formas de dominación se sustituyen (la quiebra de los supuestos instrumentales), todo ello implica una tendencia a huir de las instituciones, de la solución legal o institucional, lo que conduce a un vaciamiento progresivo de la democracia y a una huida del principio mayoritario, porque cada vez menos cosas dependen del subsistema político, de manera que se acentúa de nuevo el indiferentismo político en el sentido de que cada vez se depende menos del azar electoral, pues también cada vez importa menos cuál sea la opción ganadora. Todo este proceso se deja sentir en el ámbito del Derecho y de sus fuentes. Hay una elusión de la función general y material de la ley, hay una verdadera transacción de intereses, basado en una lógica del contrato, y se propone [como idea de Justicia] la de su conformación como instrumento mediador entre partes que llegan a un acuerdo, más que como instancia externa que aplica el Derecho objetivo. Finalmente, dentro de la quiebra de los supuestos legitimadores, la ley ha gozado de una legitimación vaga dotada de una inmediata indiscutibilidad, sigue impregnada de ese carácter que le otorga el tener su origen en la referencia imprecisa pero irresistible que es la "voluntad general"; pero su evolución posterior ha deteriorado esa fundamentación e indiscutibilidad de la ley: crisis de la representación parlamentaria; la ley pierde sus tradicionales contenidos y función de regulación; y su eficacia frente a vulneraciones. Todo ello supone un deterioro en la indiscutibilidad de la ley ${ }^{98}$.

b) Causas internas: Esta perspectiva actúa en un triple plano. La consideración de la Constitución como norma jurídica ha situado al Estado, y consiguientemente a la ley, en un segundo nivel, tanto desde una perspectiva formal

${ }^{98} \mathrm{De}$ CABO, Sobre el, cit. nota n. 4, pp. 74-78. 
como material, en donde la Constitución impone una dirección concreta a la ley, pese a que la tradición europea implicaba la defensa de la autonomía de la ley. Todo ello, además, plantea la tendencia hacia la hiperconstitucionalización del sistema; se trata de extender progresivamente el ámbito y aplicación de la Constitución reduciendo simultáneamente los de la ley, esto sigue normalmente dos vías: una es la de la extensión de los derechos y libertades, la otra es el intento de encontrar en la Constitución la regulación de todas las materias sin márgenes o con márgenes cada vez más reducidos para el legislador (para el principio democrático). Cuestión que para nada asegura el reforzamiento democrático de la Constitución, ya que ésta no es general sino selectiva. Ahora bien, otro impacto de la normativa constitucional sobre la ley, es el control que se deriva por los tribunales constitucionales (la ley, ahora, "está bajo sospecha"), generándose transferencias de poder del Parlamento al Tribunal Constitucional y simultáneamente de distorsión en gran medida del sistema de Fuentes. De ahí que se haya empezado a sostener no sólo que el legislador negativo se ha convertido en positivo, sino que se está muy próximo a realizar por parte de los tribunales constitucionales juicios de oportunidad. Otro fenómeno que se constata del nivel inferior de la ley, es lo que se denomina la "administrativización de la ley", referido al escalón inferior: la normativa y actividad administrativa; cambio que se da en dos planos, la práctica normativa y otro de construcciones dogmáticas, en donde, por ejemplo, el Ejecutivo es el que crea [la norma] y el Legislativo coadyuva a esa función. Con ello se trata de construir un Derecho constitucional despolitizado, técnico y, por ende, el que aparece más objetivo y neutro es el Derecho administrativo; en este contexto, la relación ley-Constitución debe entenderse a partir de las categorías utilizadas para comprender la relación ley-Administración. A partir de ahí se trata de aplicar la categoría de la discrecionalidad de la Administración a la relación legislador-Constitución. Y ello porque aceptada la vinculación positiva de la Administración a la ley, habría que suponer igualmente la del legislador y la ley a la Constitución en los mismos términos, es decir, se trasladarían al ámbito legislativo los criterios utilizados en el administrativo: los criterios "internos" (la motivación) y "externos" (la coherencia con el contexto, con la realidad objetiva) como parámetros para medir la arbitrariedad del legislador (por ejemplo, al amparo de los previsto en el artículo 9.3 de la Constitución española) ${ }^{99}$. Sin embargo, prosigue De Cabo, esta fundamentación es imposible adoptarla como criterio universal a la ley, ya que este tipo de intentos parece que es no sólo prescindir sino combatir el principio democrático (al menos el "realmente existente"), pues hace que los Parlamentos gocen de una situación y presunciones exorbitantes respecto de los

99 De $\mathrm{CABO}$, Sobre el, cit. nota n. 4, pp. 79-89. 
demás órganos del Estado, esto impide aceptar que la regla de la mayoría siga teniendo las virtualidades legitimadoras que justificadamente desempeñaba en un momento histórico (pues, no debe olvidarse, que a través de la regla de la mayoría se revaloriza la ley, ya que ella es la que mejor traduce el principio de igualdad). Eso sí, hay que aclarar que se trata de una posición puramente ideológica (en cuanto ideal), es decir, no real; porque esos Parlamentos de los que se habla no sólo no existieron sino que, pese a la "degeneración y corrupción partidista" de cualquiera de los Parlamentos actuales, son incomparablemente más democráticos y representativos que los estrictos Parlamentos de clase que ofrece el modelo original ${ }^{100}$.

Finalmente, dentro de esta causa interna de la transformación de la ley, cual es, el fenómeno de la administrativización de la ley, indica De Cabo que se concluye prescindiendo del principio democrático y se pasa inmediatamente al plano jurídico. Pero este paso se hace con notable incoherencia, porque se sigue afirmando un concepto de ley exclusivamente formal que, como se sabe, es el entendimiento de la ley como voluntas (de ese Parlamento que se rechaza) cuando, siguiendo con la lógica de aquel discurso, habría que concluir optando por la ley como ratio, es decir, dotada con caracteres objetivos (como la generalidad) que permitieran asegurarse frente a la desconfianza que inspira a esa tendencia el "sujeto" de donde surge. Pero -en definitiva- en lo que sí hay lógica es en ese prescindir del principio democrático. Porque, efectivamente, la arbitrariedad en el cambio político-constitucional sólo es utilizable histórica y actualmente referida al poder no democrático, es decir, "no cabe trasladar la lógica de la lucha de las inmunidades de una situación no democrática a una democrática"101.

Ahora bien, si nos adentramos en los efectos de las transformaciones que se han experimentado en el concepto de ley, se debe plantear como premisa básica, como deduce muy bien De Cabo, "que no sólo la ley sino el mismo concepto de ley sea el que haya hecho crisis"102, las razones para concluir esto son las siguientes ${ }^{103}$ :

a) No cabe seguir la tesis dualista de ley formal y ley material, pues los supuestos político-jurídicos de la actual fase del constitucionalismo democrático son incompatibles con los que servían de base a esa diferenciación;

b) No hay un concepto unitario de ley y no hay cohesión de los elementos característicos de la ley, lo que afecta el criterio de la eficacia (la fuerza de la

100 De CaBo, Sobre el, cit. nota n. 4, pp. 90-91.

101 De CABO, Sobre el, cit. nota n. 4, p. 91.

102 De CaвO, Sobre el, cit. nota n. 4, p. 97.

103 De Cabo, Sobre el, cit. nota n. 4, pp. 97-101. 
ley), al cual hay que añadir la referencia del control del Tribunal Constitucional, desapareciendo la correspondencia entre valor de ley y fuerza de ley, por consiguiente, se entiende que esos elementos ya no sirven como definitorios del concepto de ley;

c) Tampoco la definición de ley a través de un concepto exclusivamente formal (subjetivo) se considera actualmente satisfactorio, igualmente-se asegura-, el concepto formal no sirve para resolver la cuestión de las funciones del Estado, qué puede hacer el legislativo y qué puede habilitar al Ejecutivo, y, en definitiva, resolver el problema de la reserva de ley (porque es necesario señalar que precisamente la reserva de ley se mantiene y justifica porque el concepto formal no es capaz de resolver esas cuestiones, pero a costa de incurrir en contradicción por incompatibilidad clara con ese mismo concepto de ley); sin embargo, son innegables las exigencias formales de un concepto de ley para construir unitaria y coherentemente un ordenamiento jurídico, exigencias que por otra parte tampoco satisface un concepto estrictamente material ${ }^{104}$.

Pero, pese a las dificultades ya mencionadas, insiste este autor en la necesidad de llegar a un concepto unitario de ley. En la doctrina -se indica- hay varias propuestas en este punto ${ }^{105}$ :

a) A través de la generalización de la reserva en ámbitos de especial relevancia, definidos bien de manera concreta [derechos fundamentales (Häberle y García de Enterría); las tareas propias del Estado previsor (Grimm); la organización del Estado, a diferencia de los demás ámbitos que configuran lo privado (Hayek)] o bien de manera más abstracta [como el caso de Modugno], que entiende que, ante la multiplicidad actual de fuentes normativas atípicas unas respecto de las otras y con relaciones indeterminadas entre sí, no se puede hablar de un sistema de fuentes sino de distintos sistemas en relación con las distintas materias de que se trate, se propone para la ley ordinaria su configuración como norma de principio en materia de Fuentes del Derecho (Cervati, para la Constitución Italiana, utiliza la expresión igualmente de "principios" como ámbito reservado a la ley, pero como de los criterios básicos de los distintos sectores materiales sobre los que versa la legislación, de manera que la ley debe tener el carácter de "ley cuadro"). Todas estas posiciones son un acercamiento a la ley como ley material.

b) Un segundo criterio pone el acento en el procedimiento legislativo, tanto por las virtudes que comporta en orden a la racionalidad-incluso a la justicia (Stark)-, como porque sus características de discurso público, de participación de las fuerzas políticas, etc., "seleccionan" las materias en las que

104 De CaBo, Sobre el, cit. nota n. 4, pp. 100-101.

105 De Cabo, Sobre el, cit. nota n. 4, pp. 101-103. 
"Problemas teóricos en torno a las potestades normativas y la necesaria redefinición de la reserva legal en el Estado constitucional chileno"

resulta esencial ese tipo de exigencias. De acuerdo a este criterio, el concepto de ley debe ser expresión del principio democrático del Estado (social) y el principio jurídico - garantista- del Estado de Derecho, ya que en la democracia constitucional no cabe la separación entre materia y forma o que el principio formal es al mismo tiempo material; y que, en buena medida, se corresponde también con la exigencia propia del Estado social en el que el Derecho deja de ser formal y se convierte a la vez en sustantivo. De todo ello se deduce la inseparabilidad en el concepto de ley de los aspectos sustanciales y formales y la imposibilidad, en consecuencia, de un concepto que contenga uno solo de esos elementos.

Como indica De Cabo, si nos trasladamos a la esfera de la Constitución española, existe una complejidad en el sistema de fuentes de su ordenamiento. Sin embargo -se concluye-, "los distintos tipos de leyes no suponen la existencia en el ordenamiento constitucional español de distintos conceptos de ley". Es importante destacar, por último, algo muy aplicable al sistema constitucional chileno, que "es un lugar común afirmar la ambigua y paradójica relación que tienen el constitucionalismo y las constituciones con la historia: de un lado, son fruto de ella, de determinadas situaciones históricas en las que nacen y que las condicionan; de otro, tienen una vocación de permanencia, de eludir esa historia o, en todo caso y de manera más agudamente contradictoria, de prolongar indefinidamente lo que es resultado de un condicionamiento específico" ${ }^{\prime 106}$. Situados todavía en la perspectiva del ordenamiento español, indica este autor que existe, además, una perspectiva asistemática en la configuración de un criterio unitario del concepto de ley (falta de "consenso"): "Ocurre así que, en ambos aspectos, los supuestos de diferenciación normativa responden a imprevistas y erráticas exigencias coyunturales planteadas por tanto de forma asistemática. Por eso, si nunca cabe buscar en el Derecho positivo la solución o elaboración dogmática que proporcione el adecuado equipo categorial y es necesaria su "reconstrucción" doctrinal y jurisprudencial, en el caso español [también en el caso chileno, habría que agregar] y en el punto concreto de referencia es más evidente, ya que el surgimiento de los diversos tipos de leyes [o conceptos de leyes, como el caso chileno] no resulta de la lógica de un ordenamiento ni del planteamiento de una metodología sistemática para abordar necesidades objetivas, sino de deficiencias del proceso constituyente, circunstancial, empírica y casuísticamente manifestadas con posterioridad". Sin embargo, los diversos tipos de leyes -que dejan intacto el concepto de ley- se explican basándose en el principio de competencia ${ }^{107}$.

106 De Cabo, Sobre el, cit. nota n. 4, pp. 104-105.

107 De CaBo, Sobre el, cit. nota n. 4, p. 106. 
Finalmente, De Cabo plantea una importante conclusión: "Resulta, pues, que el problema no está en la supuesta ruptura del concepto de ley por la disociación de sus caracteres (clásicos) sino que donde se plantea es, de nuevo, en la manera en que se hagan presentes en la ley aquellos ingredientes de los que resultaba su significado constitucional: el principio (del Estado) democrático y el principio del Estado de Derecho con el impacto que supone el (constitucionalismo del) Estado social y con la peculiaridad antes advertida de la inseparabilidad de ambos, es decir, de la inseparabilidad en el concepto de ley de los aspectos formales y materiales" ${ }^{\prime 108}$.

Ahora bien, de lo argumentado en el corpus del presente trabajo, podemos deducir las siguientes propuestas conclusivas en torno a la necesaria redefinición de la reserva legal en Chile:

1) Existen claras deficiencias en el proceso constituyente al pretender configurarse un criterio en torno al concepto de ley, especialmente si en el mismo perviven varias nociones provenientes de diversas tradiciones constitucionales, sin que se pueda determinar con precisión cuál de las mismas ha resultado hasta ahora la más influyente. De ahí que postulemos que es posible constatar una noción material-formal de la ley en nuestra Constitución, y para desentrañar la configuración de las potestades normativas y la funcionalidad de la reserva legal, se debe inexorablemente atender, por una parte, al origen histórico de las diversas nociones de ley implícitas en la actual Carta (que proceden de ideas diferentes de acuerdo a las doctrinas clásicas), e igualmente, por la otra, se debe plantear en esta temática una diferenciación entre las dos últimas Constituciones. La particularidad que se presenta en nuestro sistema constitucional es que el paso de la Carta de 1925 a la de 1980 está acompañado por la adopción de las dos nociones de ley, tanto en un sentido material como en un sentido formal; cuestión que claramente ha generado una variación en la perspectiva de la primacía y funcionalidad de la ley en dicho tránsito constitucional, como asimismo, ha instalado una aparente incoherencia conceptual en torno al concepto de ley, que no ha sido bien comprendida hasta la fecha, y que ha dificultado compatibilizar una interacción equilibrada entre las potestades normativas en vigor.

2) En el ordenamiento constitucional se reconocen diversas clases de reserva de ley, especialmente relevante es aquella que atiende al nivel de especificidad material con que la Carta la recepta, en donde se vislumbra una reserva material y otra reserva formal de ley. El punto de inflexión de esta conclusión, hay que encontrarlo en el artículo 63, № 20, de la Constitución, que establece las denominadas "leyes de base". Este precepto ha suscitado los mayores problemas interpretativos, especialmente debido a la amplitud de su formulación, generan-

108 De Caвo, Sobre el, cit. nota n. 4, p. 107. 
"Problemas teóricos en torno a las potestades normativas y la necesaria redefinición de la reserva legal en el Estado constitucional chileno"

do un dilema teórico-conceptual respecto a la ley, dificultando, igualmente, el significado y la instrumentalización de la potestad reglamentaria independiente, la cual posee una específica esfera regulativa, como una manifestación de la ley en sentido material. Por ende, no existe una reserva negativa de ley en el sistema constitucional (donde la reserva material operaría como un límite a la capacidad regulativa del legislador, como "dominio legal máximo"), ya que coexiste, junto a la posibilidad de ordenación de la potestad reglamentaria, una verdadera "laguna material" de normativización legal, que se traduce en un problema de determinación de las realidades susceptibles de regulación; como contrapartida, tampoco existe en estricto sentido una reserva material de reglamento. De ahí que sea propio hablar de un proceso de materialización incompleta de la ley, pues el legislador chileno no ha perdido su capacidad normativa ilimitada.

3) Si bien las características de generalidad y abstracción de la ley -según la tradición del constitucionalismo liberal del siglo XVIII-, poseen un claro contenido material, otra cosa muy distinta es confundirla con el objeto sustancial normado, que en nuestro sistema, como ya se ha enfatizado en el punto anterior, posee una clara indeterminación. En consecuencia, el criterio de generalidad y abstracción instaurado por el constituyente chileno (art. 63, № 20), a fin de superar las leyes particulares o casuísticas, debe ser comprendido en el estricto sentido de aquellas cualidad objetivas de la ley, en virtud de la cual sus destinatarios (sujetos) están genéricamente determinados, y las conductas (supuestos fácticos) a las que se aplican, abstractamente consideradas. Por lo tanto, la generalidad y la abstracción son cualidades regulativas de la ley en sentido material, lo que no hay que confundir con el objeto material que es posible regular.

4) En este mismo sentido (a propósito del antes aludido artículo $63, \mathrm{~N}^{\circ} 20$ ), creemos poco justificado identificar todo rasgo material (o de contenido de ordenación legal), con el concepto de "bases esenciales", como se ha pretendido, por ejemplo, con la tesis propuesta de las "materias jurídicamente relevantes". Ello traería como resultado práctico una reserva total de ley en razón de una "esencialidad-material" altamente abstracta y difusa (como mandato de sustancia preceptiva amplia de la reserva legal), cuestión que tampoco tendría asidero constitucional, sobre todo si, además, haría inoperante el ejercicio de la potestad reglamentaria independiente (o derechamente la desconocería), no obstante tener ésta una clara consagración constitucional y sólo vinculada negativamente a la ley. Reafirmando doctrinariamente esto, cabe recordar que Léon Duguit al abordar el concepto de ley acentúa su contenido material, con la característica de ser una norma general y abstracta; de ahí que, para este autor, los reglamentos tienen también materialmente el carácter de leyes (que deben ser distinguidos de los actos administrativos), con ello la diferencia en- 
tre ley y reglamento no radica en su contenido sino en su forma, abriendo, en consecuencia, la posibilidad de dictar reglamentos que son leyes en sentido material, cuestión, esta última, claramente presente en la configuración de nuestro sistema de potestades normativas, y que, hasta ahora, parece no haber sido advertida por la doctrina mayoritaria nacional.

5) De las deducciones anteriores, habría que agregar, que la primacía regulativa de la ley convive, asimismo, con un marcado carácter no mayoritario de la decisión legislativa. Cuestión absolutamente contradictoria y paradójica, pero totalmente justificable a la luz de nuestro sistema constitucional fundamentalista, el que se sustenta en una noción de hiperconstitucionalización, que en la práctica congela la capacidad decisoria, democrático-mayoritaria, manifestada a través de la ley, lo que, sin duda, ha generado un efecto estabilizador a nivel institucional, pero que está produciendo una peligrosa desvinculación entre las decisiones estatales y los intereses de los ciudadanos, generando un claro déficit en nuestro proceso democratizador. De ahí que, en estricto sentido, no resultaría propio plantear que exista en Chile una "crisis de la ley", sino que parecería más coherente reconducir su primacía regulativa a través de un mayor impacto en su perspectiva democrático-mayoritario, especialmente aquella manifestada por vía de la decisión legislativa del Parlamento, sin obviar, asimismo, que esta reformulación de la primacía de la ley propuesta, repercutirá en nuestro sistema fundamentalista, el cual deberá ser interpretado a la luz de un constitucionalismo crítico, que aborde la dificultad para admitir, desde los parámetros de una teoría política democrática, que se impongan límites constitucionales a la capacidad de deliberación de los ciudadanos y al poder de decisión de las mayorías.

6) Ahora bien, partiendo de la base que en la actualidad es el concepto de ley el que ha hecho crisis, tanto por causas externas como por causas internas al ordenamiento jurídico, no hay que olvidar que en la intersección de lo jurídico y lo político - planos que se mezclan en la ley-, es donde resulta la coexistencia en el concepto de ley de elementos formales y materiales. Es decir, hay un elemento formal (subjetivo), ya que se trata de una norma que por su procedencia y formación expresa la manifestación de la deliberación democrática del Parlamento; y también hay un elemento material, en cuanto a través de la ley se articula el Estado con la sociedad (especialmente importante es que resuelve los supuestos competenciales de los órganos estatales y resguarda las relaciones generales de sujeción entre el Estado y los ciudadanos). Por esta razón, son innegables tanto las exigencias formales como las exigencias materiales en la elaboración de un concepto unitario de ley, ya que, por el contrario, sería imposible sustentar un concepto de ley que contenga sólo uno de esos elementos.

7) Al ser posible constatar una noción material-formal de la ley en nuestra Constitución, ello no sería precisamente una incoherencia conceptual, sino 
que, por el contrario, sería una importante base para construir un concepto unitario de ley, en donde la reserva sea una forma de revalorización de la democracia y del Estado de Derecho (es decir, logre potenciar la necesaria reciprocidad entre democracia y constitucionalismo). Esto reviste una trascendental importancia en nuestro complejo sistema de potestades normativas, ya que la originalidad del legislador nacional, que no sólo adhiere al concepto de ley material sino también al concepto de ley formal, debe compatibilizarse con la originalidad del Ejecutivo cuando ejerce su potestad reglamentaria autónoma; asimismo, ayudará a comprender que el carácter originario de la potestad reglamentaria en general tiene su fundamento en el concepto de ley en sentido material. Esto último servirá para hacer frente, entre otros importantes asuntos, a la problemática de la vinculación de la reserva con el principio de legalidad y con la potestad reglamentaria, pues bajo el término "reserva de ley", se esconden realmente dos significados distintos, uno relativo a toda la actuación administrativa y otro sólo concerniente a su potestad reglamentaria. Igualmente, esta propuesta ayudará a diferenciar la confusión existente entre reserva de ley y principio de legalidad, sobre todo, cuando se plantea la relación entre Administración y ley, ya que los efectos, de la existencia de una reserva constitucional de ley y del principio de legalidad, sobre la potestad reglamentaria, son distintos.

8) Por todo lo expresado, finalmente, es factible deducir que existe la clara necesidad de redefinir la función de la reserva legal en nuestro Estado constitucional y democrático de Derecho. Y a fin de lograr una real redefinición, inexorablemente, debemos hacernos cargo, como unidad indisoluble, de las dos aristas o ejes abordados en el presente estudio, esto es, del problema orgánicorepresentativo de nuestro Parlamento y del no fácil problema teórico-conceptual que subyace en la ley. Algunas luces, al menos, esperemos haber dado respecto a estas cuestiones.

\section{BibliografíA}

Ackerman, Bruce y Rosenkrantz, Carlos, "Tres concepciones de la democracia constitucional", Cuaderno y debates, No 29, Fundamentos y alcances del control judicial de constitucionalidad, Centro de Estudios Constitucionales, Madrid, 1991.

BAÑo LeÓn, José María, Los límites constitucionales de la potestad reglamentaria, Civitas, Madrid, 1991.

Bugueño Contreras, José, "La potestad reglamentaria autónoma en la Constitución chilena: La norma de clausura del ordenamiento jurídico", Tesis de Licenciatura, Escuela de Derecho, Universidad Católica del Norte, Coquimbo, 2012. 
Bulnes Aldunate, Luz, "Leyes de Base y Potestad Reglamentaria en la Constitución de 1980", Revista de Derecho de la Universidad Católica de Valparaíso, $\mathrm{N}^{\circ} 6,1982$.

Bustos Ramírez, Juan y Hormazábal Malarée, Hernán, Lecciones de Derecho Penal chileno, vol. I, Librotecnia, Santiago, 2012.

Caldera Delgado, Hugo, Tratado de Derecho Administrativo, Tomo II, Ediciones Parlamento, Santiago, 2001.

Carmona Santander, Carlos, "Tres problemas de la potestad reglamentaria: estado de la cuestión y proyecciones", Revista de Derecho del Consejo de Defensa del Estado, Año 1, № 3, 2001.

CARré de MalberG, Raymond, La ley, expresión de la voluntad general. Estudio sobre el concepto de ley en la Constitución de 1875, Marcial Pons, Madrid, 2011.

Cazor Aliste, Kamel, La sumisión a Derecho de los actos y disposiciones del Presidente de la República, Tomo I, Ediciones Universidad Central de Chile, Santiago, 2002.

Cazor Aliste, Kamel y Guiloff Titiun, Matías, "Problemas conceptuales y de funcionalidad de la reserva legal en Chile", Las Fuentes Formales del Derecho Público (Coordinador Hugo Tórtora), Editorial Metropolitana, Santiago, 2012.

Cazor Aliste, Kamel y Pfeffer Urquiaga, Emilio, "La búsqueda de criterios orientadores en la configuración de la potestades normativas en Chile", lus et Praxis, vol.15, n.1, 2009.

CAzor Alıste, Kamel, "Regulación reglamentaria v/s regulación legislativa", Revista de Derecho Universidad Católica del Norte, año 18, n. 2, 2011.

Cazor Aliste, Kamel, "¿Reserva material del reglamento en el sistema constitucional chileno? Comentario a propósito de la sentencia del Tribunal Constitucional Rol No 591/2006", Revista de Derecho, Universidad Católica de Valparaíso, XXXVII Jornadas de Derecho Público, 2007.

Cea Egaña, José Luis, "Dominio legal y reglamentario en la Constitución de 1980", Revista Chilena de Derecho, vol. 11, 1984.

ComanducCl, Paolo, "Formas de (Neo) constitucionalismo: un análisis metateórico", Coordinador Miguel Carbonell, Neoconstitucionalismos, Trotta, Madrid, 2005.

Cordero Quinzacara, Eduardo, "El sentido actual del dominio legal y la potestad reglamentaria", Revista de Derecho de la Universidad Católica de Valparaíso, vol. 32, 2009.

De Cabo Martín, Carlos, Sobre el concepto de ley, Editorial Trotta, Madrid, 2000. 
Duguit, Léon, Lecciones de Derecho público general, Marcial Pons, Madrid, 2011.

Elster, Jon y SLAGSTAD, Rune, Constitucionalismo y democracia, Fondo de Cultura Económica, México, 1999.

Fernández González, Miguel Ángel, "Antecedentes históricos y jurisprudenciales acerca de la potestad reglamentaria autónoma" (Coordinadores Jaime Arancibia y José Ignacio Martínez), La primacía de la persona: Estudios en homenaje al profesor Eduardo Soto Kloss, LegalPublishing, Santiago, 2009.

Ferreres Comella, Víctor, Una defensa del modelo europeo de control de constitucionalidad, Marcial Pons, Madrid-Barcelona, 2011.

García Pino, Gonzalo, La reserva legal de derechos constitucionales: ipoder legislativo contra la administración? Ediciones Universidad Alberto Hurtado, Santiago, 2004.

Gomes Canotilho, José Joaquín, Teoría de la Constitución, Dykinson, Madrid, 2004.

Henríquez Viñas, Miriam, Las fuentes formales del Derecho, LegalPublishing, Santiago, 2009.

LóPEZ Aguilar, Juan Fernando, "La reserva constitucional de ley en materia penal", Revista Española de Derecho Constitucional, № 33, 1991.

López Guerra, Luis, "Carré de Malberg: de la soberanía nacional a la soberanía popular", Introducción al libro La ley, expresión de la voluntad general (Estudio sobre el concepto de la ley en la Constitución de 1875), Marcial Pons, Madrid-Barcelona, 2011.

MacCormick, Neil, "Constitucionalismo y democracia", Anuario de Derechos Humanos, Universidad Complutense de Madrid, 1988-89, № 5.

Melero Alonso, Eduardo, "La flexibilización de la reserva de ley", Revista Jurídica Universidad Autónoma de Madrid, n. 10, 2004.

MerkL, Adolf, Teoría General del Derecho Administrativo, 1953, Madrid, Editorial Revista de Derecho Privado, Madrid, 1953.

Molina Guaita, Hernán, Derecho Constitucional, Editorial Andalién, Concepción, 1998.

Moraga Klenner, Claudio, "La actividad formal de la Administración del Estado" (Coordinador Rolando Pantoja), Tratado de Derecho Administrativo, LegalPublishing, Santiago, 2010.

Pantoja BAuZÁ, Rolando, "La relación entre ley y reglamento en el Derecho chileno", Revista de Derecho del Consejo de Defensa del Estado, № 20, 2008.

Pascual Medrano, Amelia, "La ley y el reglamento en el Derecho Constitucional francés", Revista de Estudios Políticos (Nueva Época), Núm. 106, 1999. 
Peña Freire, Antonio, "Constitucionalismo Garantista y Democracia", Revista Crítica Jurídica, 2003, № 22.

Pérez Royo, Javier, Las fuentes del Derecho, Tecnos, Madrid, 2007.

Rebollo Puig, Manuel, "Juridicidad, legalidad y reserva de ley como límites a la potestad reglamentaria del Gobierno", Revista de Administración Pública, $\mathrm{N}^{\circ} 125,1991$.

Ribera Neumann, Teodoro, "Reserva legal, potestad reglamentaria y Constitución de 1980", Revista de Derecho Público, vol. 63, 2001.

Ribera Neumann, Teodoro, "Reserva legal y potestad reglamentaria en la Constitución de 1980. Antecedentes inéditos de la Junta de Gobierno", Documento inédito, 2000.

SChneider, Hans Peter, Democracia y Constitución, Centro de Estudios Constitucionales, Madrid, 1991.

Tremeau, Jérôme, La Réserve de loi. Compétence Législative et Constitution, Presses Universitaires D’Aix-Marsielle, Aix-en-Provence, 1997.

Verdugo MarinKovic, Mario, "Asamblea constituyente: ¿Invitación a un quiebre institucional?", Diario Constitucional, 2012. En: http://diarioconstitucional. cl/mostrararticulo.php?id=192 [visitado el 03/09/2012].

Villacorta Mancebo, Luis, Reserva de ley y Constitución, Editorial Dykinson, Madrid, 1994.

ZúÑIGa URBINA, Francisco, "Leyes de Bases en la Jurisprudencia del Tribunal Constitucional: Apuntes acerca de la norma de clausura", Revista de Derecho de la Universidad Católica de Valparaíso, Vol. 23, 2002. 